Check for updates

Cite this: Mater. Chem. Front. 2020, 4, 3176

Received 26th July 2020,

Accepted 31st August 2020

DOI: 10.1039/d0qm00540a

rsc.li/frontiers-materials

\section{Naphthalene diimide- and perylene diimide-based supramolecular cages}

\author{
Qing-Hui Ling, ${ }^{a}$ Jun-Long Zhu, ${ }^{a}$ Yi Qin ${ }^{\star a}$ and Lin Xu (D) *ab
}

During the past few years, the construction of naphthalene diimide (NDI)- and perylene diimide (PDI)based cages has attracted increasing attention due to the unique photo- and electrochemical properties and widespread applications of these materials in catalysis, chemical separation, sensing, etc. Thus, it is the right time to summarize the recent development of NDI-/PDI-based cages. In this review, the preparations, properties, and applications of NDI-/PDI-based cages in catalysis, chemical separation, and sensing will be discussed.

\section{Introduction}

Since the discovery of crown ethers and cryptands by Lehn et al., the construction of new supramolecular hosts, including macrocycles and cages, has attracted increasing interest. ${ }^{1}$ Compared to two-dimensional macrocycles such as pillar $[n] \operatorname{arene}^{2}$ and metalcoordinated macrocycles, ${ }^{3}$ which possess an open cavity and allow guests to fill a hole or bind on the surface of the macrocycle, threedimensional cages possess enclosed cavities in which guests are entirely encapsulated in the confined space in general. Due to the efficient encapsulation of various guests, cages could thus be applied in many fields, such as molecular recognition, catalysis,

${ }^{a}$ Shanghai Key Laboratory of Green Chemistry and Chemical Processes, School of Chemistry and Molecular Engineering, East China Normal University, 3663 N. Zhongshan Road, Shanghai 200241, China.

E-mail: qinyihuaxue@126.com,lxu@chem.ecnu.edu.cn

${ }^{b}$ State Key Laboratory of Fine Chemicals, Dalian University of Technology, Dalian 116024, P. R. China chemical transfer and separation, and stabilization of reactive intermediates. ${ }^{4}$ During the past few decades, a variety of cages with structural complexity, including Platonic and Archimedes polyhedrons, were reported and exhibited unique properties and functions, ${ }^{5}$ which promoted the development of modern supramolecular chemistry.

Rylene diimides (RDIs, $n=0-7$ ) are a series of aromatic diimides; for example, $n=0$ or 1 , corresponded to naphthalene diimide (NDI) and perylene diimide (PDI), respectively (Scheme 1). NDI and PDI have attracted extensive attention due to their large planar structure, electron-deficient nature, photochemical and electrochemical properties (strong absorption in the visible region, high quantum yield and redox activity), and easy functionalization. ${ }^{6}$ Therefore, in the past few decades, a large number of NDI and PDI derivatives have been prepared with applications in sensing, light harvesting, photocatalysis and supramolecular self-assembly. ${ }^{7}$ For example, some NDI- and PDI-based macrocycles were successfully

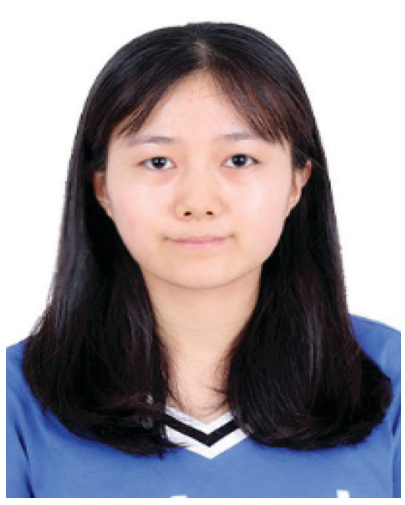

Qing-Hui Ling
Qing-Hui Ling received her BS degree in applied chemistry from Anhui University of Science and Technology in 2019. She is now pursuing her MS degree in Prof. Hai-Bo Yang's group at East China Normal University. Her research interests focus on the design and synthesis of functional fluorescent metallacages.

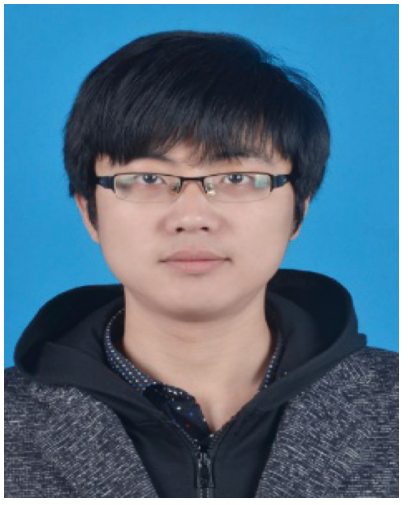

Jun-Long $\mathrm{Zhu}$ received his $B S$ degree in chemistry from Zhengzhou University in 2016. He is now pursuing his PhD degree in the group of Prof. HaiBo Yang at East China Normal University. His research interests focus on the functional luminescent metallocycles and metallacages. 


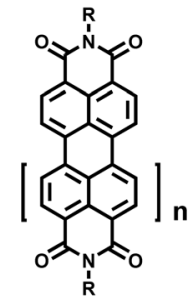

RDIs ( $n=0-7$ )

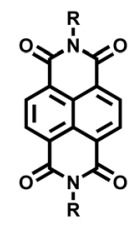

NDI

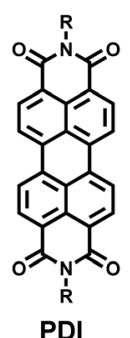

PDI
Scheme 1 Chemical structures of NDI and PDI

constructed through covalent synthesis or non-covalent selfassembly. ${ }^{8}$ Since NDI and PDI derivatives exhibit excellent photochemical and electrochemical properties, integrating NDI or PDI subunits into a cage may result in distinctive properties and functions: (1) the electron-deficient nature of NDI/PDI could endow the cage with a strong affinity for electron-rich guests such as $\mathrm{C}_{60}$; (2) the switchable redox activity of NDI/PDI endows the cage with catalytic performance; and (3) a cage with strong absorption in the visible region may serve as a visible-light photocatalyst. In recent decades, a series of NDI-/PDI-based cages were constructed, and their properties and applications were investigated in detail. It should be noted that among the NDI/PDI cages, metal-coordinated cages are in the majority since coordinationdriven self-assembly has proven to be a powerful tool to construct various supramolecular architectures, including three-dimensional metal-coordinated cages. ${ }^{9}$ In addition, due to the linear structure of NDI/PDI units, tetrahedral cages were readily prepared through coordination-driven selfassembly. ${ }^{10}$

This review will focus on the preparation strategies, photochemical and electrochemical properties of NDI/PDI-based cages as well as their applications. For clarity, this review will be classified into NDI-based cages and PDI-based cages.

\section{Naphthalene diimide-based cages}

Naphthalene diimide (NDI) derivatives are planar and electrondeficient as well as $\pi$-acidic and can be used in anion- $\pi$ catalysis. ${ }^{11}$ Typically, NDI derivatives could undergo two reversible one-electron reduction under chemical or electrochemical conditions with half-wave potentials of $-1.10 \mathrm{~V}$ and $-1.51 \mathrm{~V} v s$. $\mathrm{Fc} / \mathrm{Fc}^{+}$in $\mathrm{CH}_{2} \mathrm{Cl}_{2} \cdot{ }^{6 a}$ Based on the outstanding features of NDI units and the confined space of cages, NDI-based cages show unique physical and chemical properties and can be applied in various fields, such as catalysis, sensing, and separation of anions.

Nitschke and co-workers have made significant contributions in the field of NDI-based cages. In 2013, Nitschke, Schalley and Sanders et al. reported the synthesis of a tetrahedral NDI cage and investigated its mechanically interlocked behaviour with bis-1,5-(dinaphtho)-[38]crown-10. ${ }^{12}$ As shown in Fig. 1, by treating NDI-containing diamine 1, 2-formylpyridine and $\mathrm{Fe}\left(\mathrm{NTf}_{2}\right)_{2}$ in a ratio of $6: 12: 4$ in acetonitrile at $50{ }^{\circ} \mathrm{C}$ for $24 \mathrm{~h}$, an $\mathrm{M}_{4} \mathrm{~L}_{6}$-type NDI cage 2 was obtained through subcomponent self-assembly. The NDI cage 2 was well characterized by ${ }^{1} \mathrm{H}$ NMR, ESI-MS, COSY, and NOESY NMR spectroscopy, and the broadening and overlap of the signals in the ${ }^{1} \mathrm{H}$ NMR spectra indicated the existence of various diastereomers with $T, S_{4}$, and $C_{3}$ symmetry of the cage in solution. Due to their planar structure and electron-deficient properties, NDI derivatives readily form donor-acceptor complexes with aromatic species. Thus, NDI cage 2 was further treated with bis-1,5-(dinaphtho)-[38]crown-10 (10 equiv.) 3 , and three-dimensional polycatenanes were formed. The ${ }^{1} \mathrm{H}$ NMR spectrum of the polycatenanes showed two sets of signals, in which one signal corresponded to the crown etherbound NDI cage (an upfield shift in ${ }^{1} \mathrm{H}$ NMR relative to the initial NDI cage 2) and the other signal corresponded to the free NDI cage. The above result also suggested the slow exchange process between the bound and free crown ether on the NMR timescale. In addition, the mixtures of polycatenanes cannot be

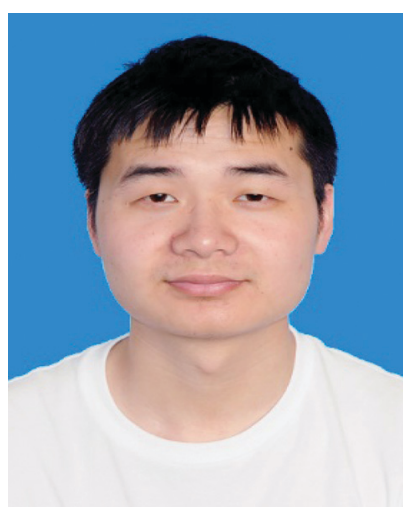

Yi Qin
$Y i$ Qin received his BS degree in chemistry from Central China Normal University in 2015. Then he joined Prof. Hai-Bo Yang's group at East China Normal University and obtained his $P h D$ degree in chemistry in 2020. His research interests are focused on photofunctional organometallic self-assembly systems.

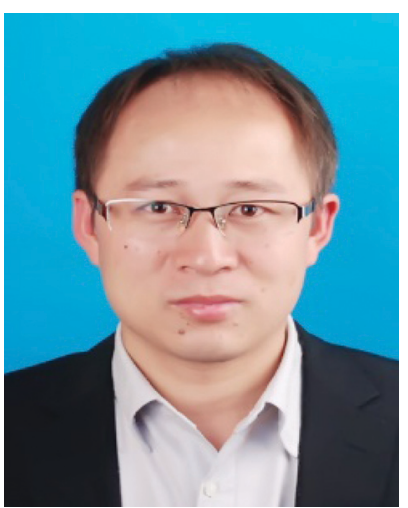

Lin Xu
Lin $X u$ received his $P h D$ degree in Chemistry from the East China University of Science and Technology (ECUST, Shanghai) in 2012 under the supervision of Professor Xuhong Qian. Subsequently, he joined the East China Normal University (ECNU, Shanghai) as an assistant professor and was promoted to an associate professor and a full professor in 2014 and 2018, respectively. He carried out twoyears postdoctoral research at the University of Cambridge with Prof. Jonathan Nitschke during 20152017. His research interests focus mainly on the supramolecular fluorescent chemistry. 

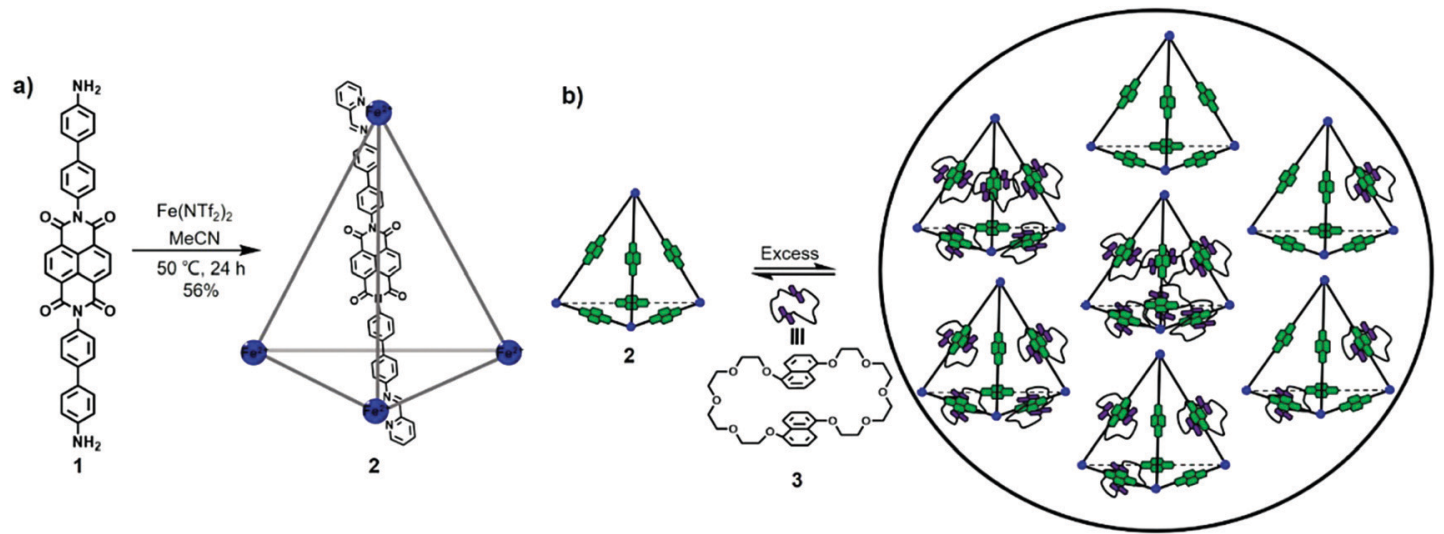

Fig. 1 (a) Synthesis of tetrahedral cage 2. (b) Graphical representation of the polycatenanes formed upon the addition of excess crown ether 3 into cage 2.

distinguished in NMR spectra due to the overlapping signals. Furthermore, treatment of NDI cage 2 with a large excess of 3 (38 equiv.) provided saturated [7]catenane. DOSY spectra of the polycatenanes also showed two groups of resonances corresponding to the crown ether-bound NDI cages and the free crown ether, consistent with the ${ }^{1} \mathrm{H}$ NMR spectra. An infrared multiphoton dissociation (IRMPD) tandem MS experiment was further performed to confirm the specific binding between the NDI cages and crown ethers, and the results indicated that $\left[\mathrm{M}_{4} \mathrm{~L}_{6} \mathrm{C}_{7}\right]^{8+}(\mathrm{C}=$ catenated crown ether 3$)$ showed non-specific binding between NDI cage 2 and crown ether 3 , while $\left[\mathrm{M}_{4} \mathrm{~L}_{6} \mathrm{C}_{6}\right]^{8+}$ ions maintained their tetrahedral structure with six catenated crown ethers. Furthermore, the binding isotherm revealed that the binding of the six crown ethers to the NDI cage was not cooperative due to the relatively large space for threading, and the binding constant was determined to be $794 \pm 34 \mathrm{~L} \mathrm{~mol}^{-1}$. In conclusion, this work successfully constructed three-dimensional polycatenanes through three reversible interactions (metal-ligand coordination, imine bond, and donor-acceptor interactions) and studied the dynamic systems in detail, laying the foundation for the construction of new molecular machines with various applications.

The exploration of synthetic chemical systems that respond to different stimuli can offer insight into the signalling events and new means to synthesize useful stimuli-responsive systems and materials. Nitschke, Schalley and Sanders et al. reported NDI- and porphyrin-based mixed-ligand tetrahedral cages and studied their stimulus-responsive behaviour upon catenation and guest encapsulation. ${ }^{13}$ As shown in Fig. 2 a, two different cages, 5 and 7, based on NDI and porphyrin, respectively, were readily obtained through subcomponent self-assembly. The crystal structures of $\mathbf{5}$ and $\mathbf{7}$ confirmed their tetrahedral structure, and the NDI ligand and the porphyrin ligand showed almost the same length $(18.4 \AA)$, suggesting the possibility of ligand exchange upon mixing of the two cages. In addition, interactions between the NDI and porphyrin cages with crown ether 3 and $\mathrm{C}_{70}$ were investigated (Fig. 2b). The results indicated that at most two equivalents of crown ethers 3 could thread onto the NDI moiety in cage $\mathbf{5}$, which was less than its analogue 2 (at most 6 crown ethers), probably due to the steric strain between the adjacent NDI moieties resulting from the smaller space in cage $\mathbf{5}$. In addition, $\mathbf{5}$ showed no host-guest interaction with $\mathrm{C}_{70}$ due to the existence of large pores in its external surface, whereas porphyrin cage 7 could form a hostguest complex with $\mathrm{C}_{70}$. Furthermore, in order to investigate the structural reconstitutions through catenation and guest encapsulation, NDI-based cage $\mathbf{5}$ and porphyrin-containing cage 7 were mixed in a $1: 1$ ratio at $25{ }^{\circ} \mathrm{C}$ for $24 \mathrm{~h}$ and a dynamic combinatorial library (DCL) of mixed-ligand tetrahedral cages was obtained (Fig. 2c). Because the species in the DCL had similar ESI-response factors, ESI-MS could be used to evaluate the content of each species. The results indicated that upon simple mixing, various species were observed, and species $\mathbf{4}_{\mathbf{4}} \mathbf{6}_{\mathbf{2}}$ and $\mathbf{4}_{\mathbf{1}} \mathbf{6}_{\mathbf{5}}$ (the subscripts indicate the number of ligands in one cage) were in the majority, which deviated from the principle of Pascal's triangle, revealing that minor differences in the ligand will largely affect the final results of self-assembly and that the ligands tend to form homoleptic assemblies through self-sorting. In addition, upon addition of $\mathrm{C}_{70}$ into the DCL, the final composition was almost complete for $\mathbf{5}$ and $\mathbf{C}_{\mathbf{7 0}} \subset \mathbf{7}$ species because the host-guest adduct $\mathbf{C}_{\mathbf{7 0}} \subset \mathbf{7}$ was thermodynamically stable. Upon the addition of crown ether $\mathbf{3}$ into the DCL, $\mathbf{4}_{\mathbf{4}} \mathbf{6}_{\mathbf{2}}$ and $\mathbf{4}_{\mathbf{1}} \mathbf{6}_{\mathbf{5}}$ appeared with the highest abundance to meet the requirement of the maximum degree of catenation, thus maximizing the number of $\pi$-interactions between NDI and naphthalene. This work constructed an elaborate dynamic system that showed a response to catenation and host-guest encapsulation, which was helpful for understanding the stimulus-responsive behaviours of biological systems.

In 2015, Nitschke and co-workers reported the construction of an NDI-based heteroleptic metal-organic cage through the donor-acceptor interaction of pyrene and NDI. ${ }^{14}$ As shown in Fig. 3, reaction of the pyrene-containing diamine 8 or $\mathbf{1 1}$, 2-formylpyridine, and metal ions $\left(\mathrm{Fe}^{2+}, \mathrm{Zn}^{2+}\right.$ or $\left.\mathrm{Co}^{2+}\right)$ in a ratio of $6: 12: 4$ afforded two $\mathrm{M}_{4}^{\mathrm{II}} \mathrm{L}_{6}$ type cages, 9 and 12 , respectively. $\mathrm{X}$-ray diffraction analysis indicated that cage $\mathbf{9}$ showed a $C_{2}$-symmetric rhomboidal structure with mer metal coordination 

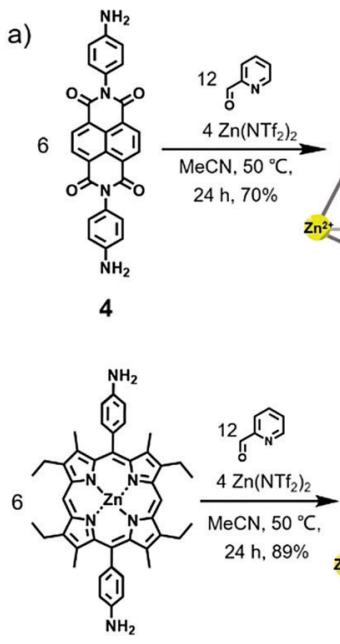

6

c)
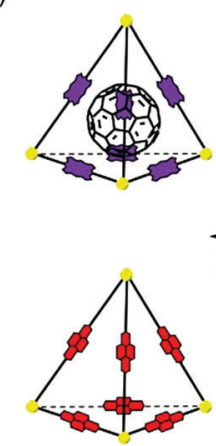
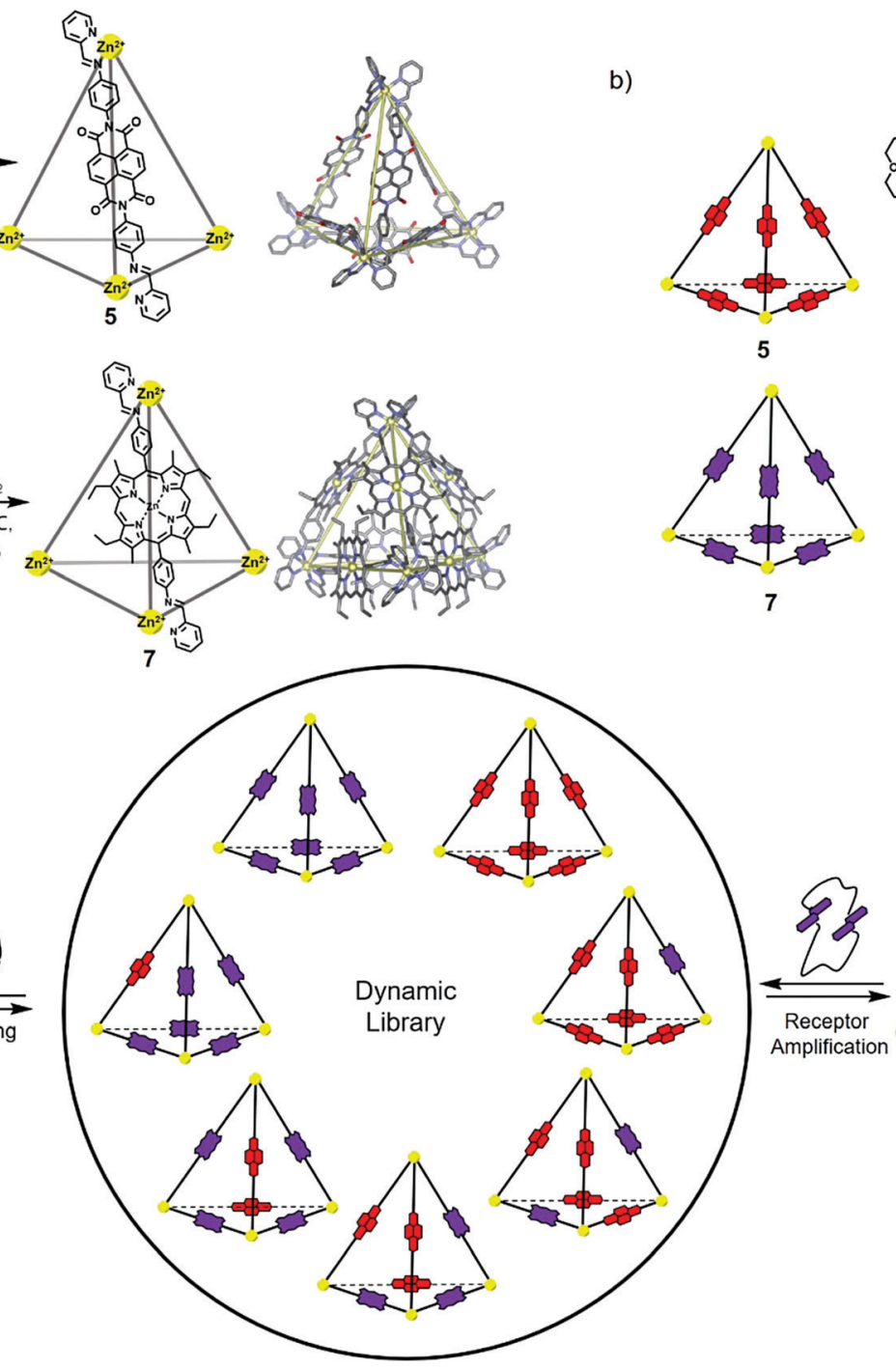

b)
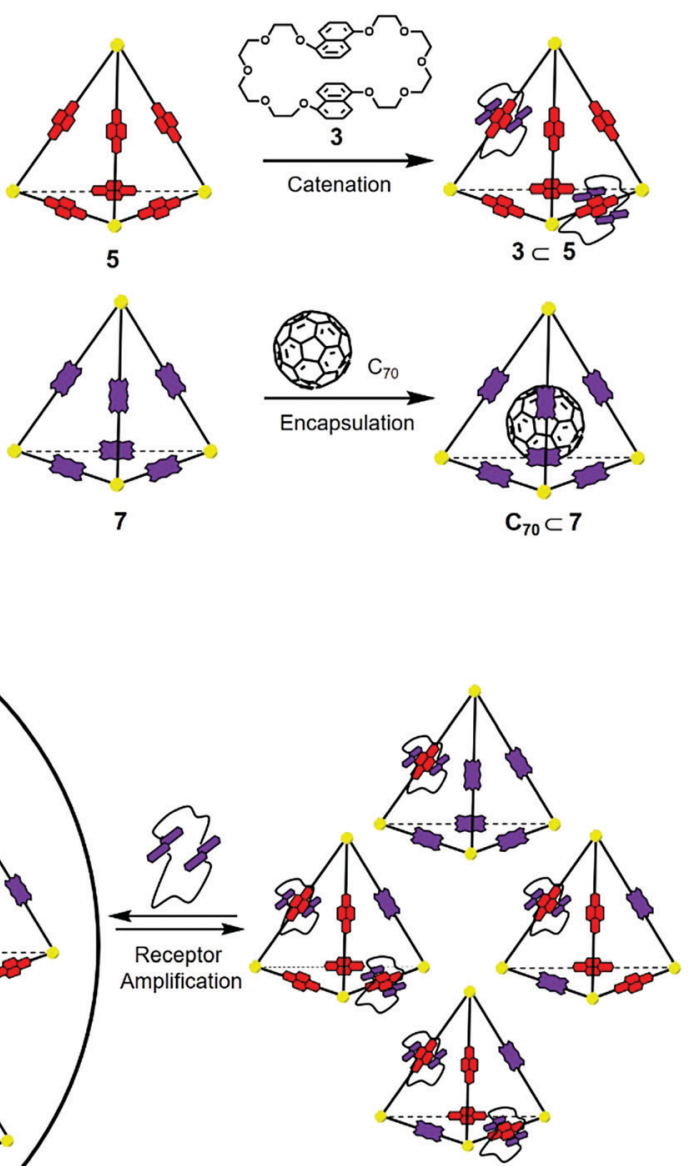

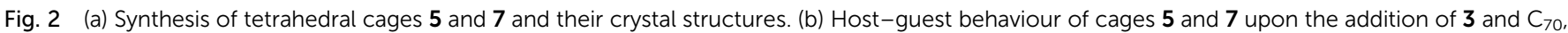

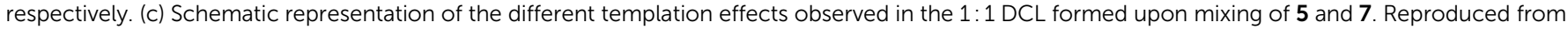
ref. 13 with permission from Royal Society of Chemistry, copyright 2016.

and that cage 12 showed a $C_{3}$-symmetric pseudotetrahedron with fac metal coordination. These structures were obviously different from the common tetrahedral $\mathrm{M}_{4}^{\mathrm{II}} \mathrm{L}_{6}$ cages, which was ascribed to the $\pi$-stacking of pyrene subunits. In addition, the reaction of pyrene-containing diamine 11, 2-formylpyridine and metal ions $\left(\mathrm{Zn}^{2+}\right.$ or $\left.\mathrm{Co}^{2+}\right)$ in a ratio of $6: 12: 6$ provided a box-like structure 13 that could encapsulate electron-deficient guests such as NDI, which inspired the authors to construct heteroleptic cages through donor-acceptor interactions. By mixing box 13 with additional NDI-based diamine $\mathbf{4}$ or the reaction of pyrenecontaining diamine 11, NDI-based diamine 4, 2-formylpyridine and metal ions $\left(\mathrm{Fe}^{2+}, \mathrm{Zn}^{2+}\right.$ or $\left.\mathrm{Co}^{2+}\right)$ in a ratio of $4: 2: 12: 4$ afforded heteroleptic cage 14. X-ray diffraction analysis indicated that cage 14 adopted an elongated sandwich-like structure due to the internal pyrene-pyrene-NDI stacks. This donor-donor-acceptor arrangement was complementary to the common donor-acceptor interactions. Further self-sorting experiments were performed to investigate the universality of the construction of heteroleptic cages. As shown in Fig. 4, due to the thermodynamic stability of 14, it was readily obtained via integrative self-sorting. However, a mixture of 8 and 4,2-formylpyridine and $\mathrm{Zn}\left(\mathrm{NTf}_{2}\right)_{2}$ in $\mathrm{CD}_{3} \mathrm{CN}$ resulted in homoleptic cages $\mathbf{Z n - 1 5}$ and $\mathbf{Z n - 1 0}$, which revealed that the process was narcissistic self-sorting. In addition, by treatment of $\mathbf{1 6}$ (or 17) and 4 under the same conditions, a mixture of seven assemblies was observed, and a dynamic combinatorial library (DCL) was formed (similar to the results by mixing cages 5 and 7 without templation effects), which was ascribed to the absence of $\pi$-stacking between pyrene and NDI units. In conclusion, an NDIbased heteroleptic cage was successfully constructed through donor-acceptor interactions, which provided a new method to construct metal-organic cages with more complexity.

Supramolecular catalysts, such as metal coordinated cages, have been widely applied in molecular synthesis. ${ }^{15}$ In 2019, Nitschke et al. reported the synthesis of an NDI-based tetrahedral 


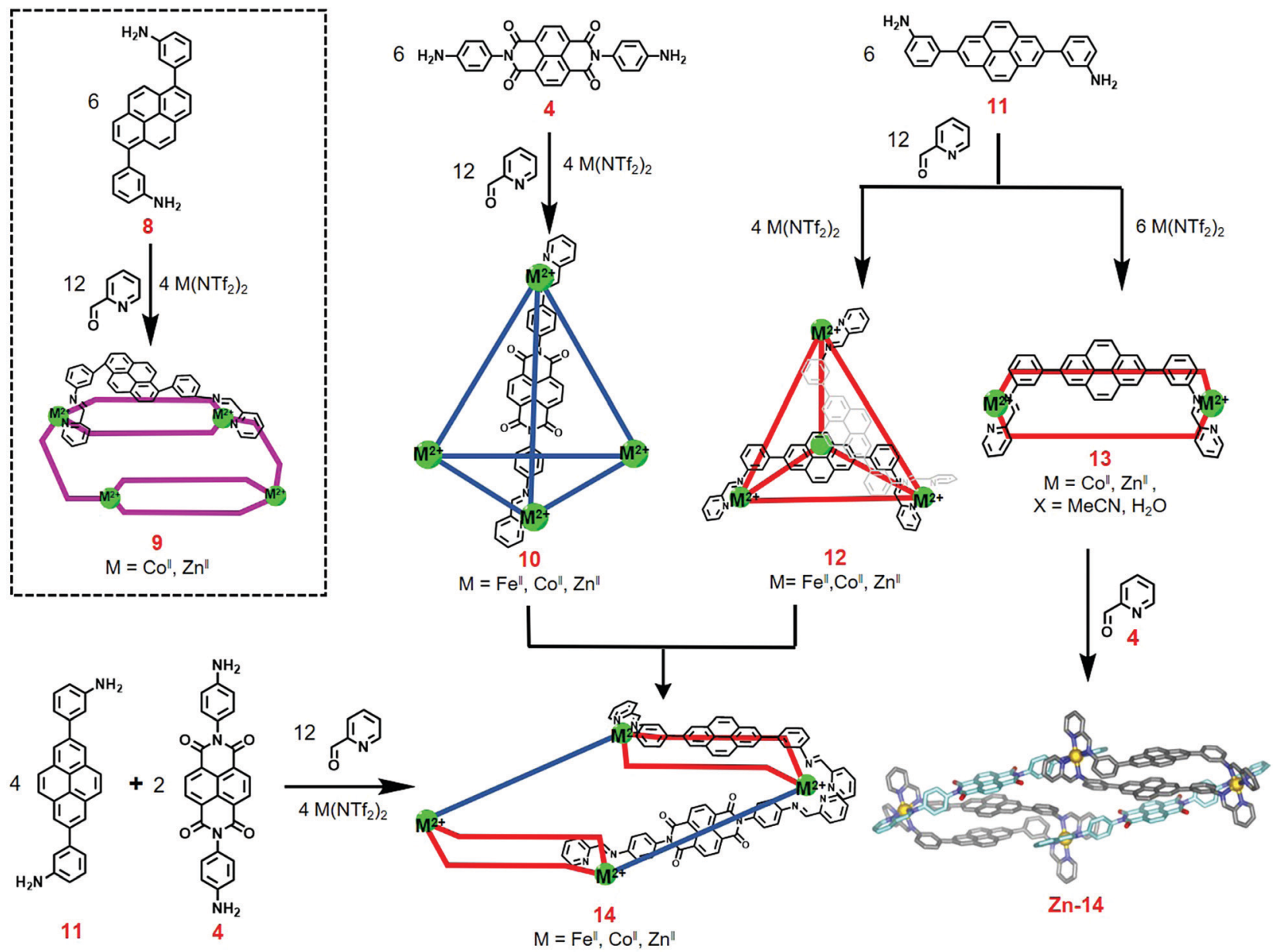

Fig. 3 Synthesis of cages $\mathbf{9}, \mathbf{1 0}, \mathbf{1 2}, \mathbf{1 3}$, and 14 and crystal structure of cage $\mathbf{Z n - 1 4}$. Reproduced from ref. 14 with permission from American Chemical Society, copyright 2015.

cage with redox-switchable behaviour and could serve as a catalyst for $\mathrm{C}-\mathrm{C}$ bond coupling. ${ }^{16}$ As shown in Fig. 5, treating NDIcontaining diamine 18 and 2-formylpyridine with $\mathrm{Zn}\left(\mathrm{NTf}_{2}\right)_{2}$ in acetonitrile afforded NDI cage 19 with a yield of $77 \%$. NDI cage 19 was well characterized by NMR and ESI-MS spectra. Furthermore, cyclic voltammetry (CV) experiments were conducted to investigate the redox properties of 19, and the results indicated that 19 showed two reduction peaks at $-1.1 \mathrm{~V}$ and $-1.52 \mathrm{~V}$ vs. $\mathrm{Fc} / \mathrm{Fc}^{+}$, corresponding to the NDI moieties. In addition, upon the addition of cobaltocene $\left(\mathrm{Cp}_{2} \mathrm{Co}\right)$ and tetrachloro-1,4-benzoquinone, the cage could be reversibly reduced and re-oxidized without disturbing the cage's framework. ${ }^{1} \mathrm{H}$ NMR spectra indicated that the cage could form a host-guest complex with $\mathrm{C}_{60}$ derivative 20. Moreover, tetrakis(4-chlorophenyl)borate 21 was used in place of $\mathrm{Cp}_{2} \mathrm{Co}$ as the reductant, and the ${ }^{1} \mathrm{H}$ NMR and EPR spectra revealed the generation of radical species. Interestingly, the formation of $4,4^{\prime}$-dichlorobiphenyl was also observed during the reduction, which inspired the authors to investigate the cage as a catalyst for the $\mathrm{C}-\mathrm{C}$ bond coupling of organoborates. Further experiments indicated that the host-guest complex $\mathbf{2 0} \subset \mathbf{1 9}$ exhibited a two-fold increase in yield during the catalytic process relative to cage 19 alone, and the control compound, such as the NDI ligand, showed no catalysis. In addition, complex $20 \subset 19$ could catalyse the coupling of organoborates with both electronwithdrawing and electron-donating groups, which was complementary to common coupling catalysis. EPR experiments were performed to investigate the catalytic mechanism, and the results indicated that $\mathrm{C}_{60}$ derivative $\mathbf{2 0}$ could serve as a radical-stabilizing agent to stabilize the radical species of the cage. Thus, the catalytic performance occurred on the surface of the cage, and $\mathrm{C}_{60}$ acted as a co-catalyst to enhance the catalytic activity for the oxidative coupling of organoborates, which afforded a new view into supramolecular catalysis.

Molecular sensing plays an important role in supramolecular chemistry. In 2020, Valiyaveettil et al. reported the construction of a NDI-based water-soluble macrocycle which contains quaternary ammonium groups. ${ }^{8 i}$ The macrocycle exhibited high affinity for aromatic carboxylate anions such as perylene tetracarboxylate tetrapotassium salt $\left(K_{\mathrm{sv}}=1.6 \times 10^{5} \mathrm{M}^{-1}\right)$ and biphenyl-4,4'dicarboxylic acid dipotassium salt $\left(K_{\mathrm{sv}}=4.3 \times 10^{4} \mathrm{M}^{-1}\right)$, due to the electrostatic interactions between cationic macrocycle and anionic guests, size matching effect and the interaction between electron-deficient NDI units and aromatic perylene. 

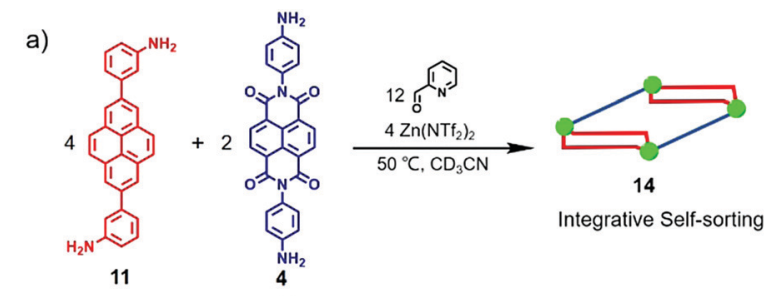

b)
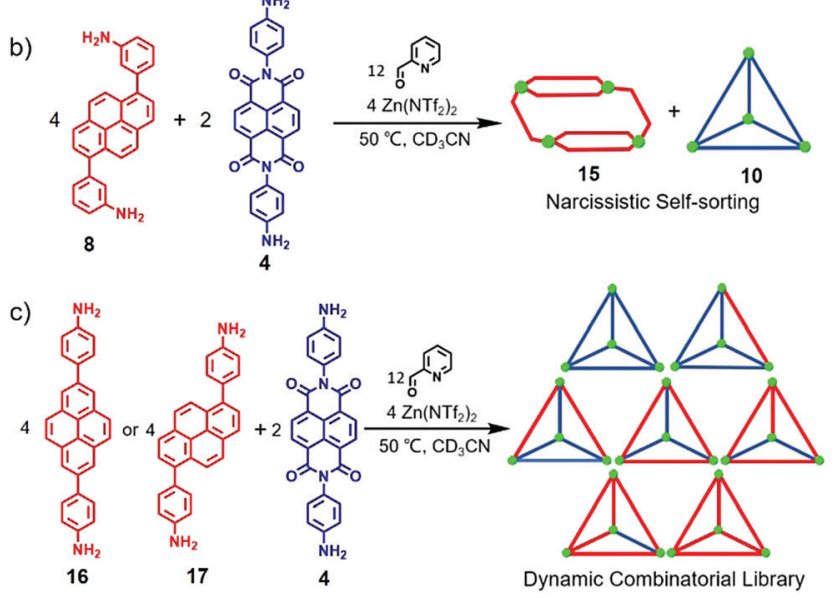

Fig. $4(a-c)$ Results of subcomponent self-assembly with mixtures of various diamines.

Considering the redox-active properties of NDI, at the same year, Nitschke and co-workers reported the synthesis of a NDIbased cage with redox-responsive guest uptake and release behaviour. ${ }^{17}$ Notably, the addition of excess reductant $\mathrm{Cp}_{2} \mathrm{Co}$ into cage 19 led to the formation of precipitation resulting from charge neutralization (the negatively charged NDI panels were compensable to the cationic charges of $\mathrm{Zn}^{2+}$ vertices), which hampered the further study in solution. Thus, quaternary ammonium-functionalized NDI ligand 23 in place of ligand 18 was prepared to construct the new NDI cage $\mathbf{2 4}$ (Fig. 6). X-ray crystallographic analysis indicated that the cage adopted the typical tetrahedral structure, and three carborate anions were encapsulated in the cage due to the multiple positive charges of 24. CV experiments indicated that cage $\mathbf{2 4}$ showed two reduction peaks at $-0.81 \mathrm{~V}$ and $-1.19 \mathrm{~V} v s$. $\mathrm{Fc} / \mathrm{Fc}^{+}$and two oxidation peaks at $-1.29 \mathrm{~V}$ and $-0.78 \mathrm{~V}$. It should be noted that the reduction peaks were reversible, while they were irreversible for the NDI ligand 23, indicating the self-assembled cages enhanced the robustness of NDI units under redox process. Thus, the cage could be reversibly reduced and re-oxidized upon the addition of $\mathrm{Cp}_{2} \mathrm{Co}$ and $\mathrm{AgNTf}_{2}$. In addition, ${ }^{1} \mathrm{H}$ NMR experiments demonstrated that cage 24 could bind only anion species such as $\mathrm{BF}_{4}{ }^{-}, \mathrm{PhBF}_{3}{ }^{-}$and $\mathrm{CB}_{11} \mathrm{H}_{12}{ }^{-}$instead of neutral species due to its multiple positive charges. Furthermore, the redox-responsive guest uptake and release behaviour of the cage was investigated, and the results indicated that the guest $\mathrm{PhBF}_{3}{ }^{-}$was ejected from the cage upon reduction with $\mathrm{Cp}_{2} \mathrm{Co}$, while with the subsequent addition of $\mathrm{AgNTf}_{2}$, the guest could be re-taken up (Fig. 6b). It should be noted that cage $\mathbf{2 4}$ exhibited a suitable volume for binding with fullerenes, which

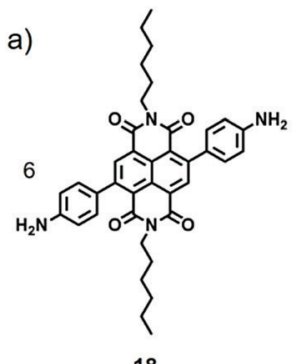

18

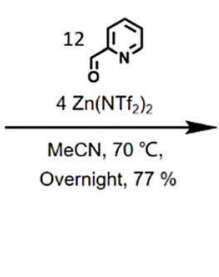

b)

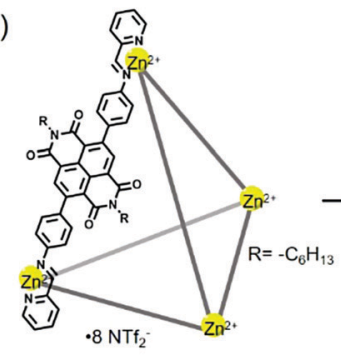

19

c)

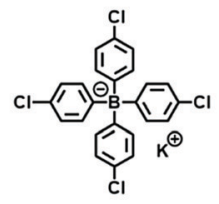

21

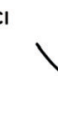

$20 \subset 19$

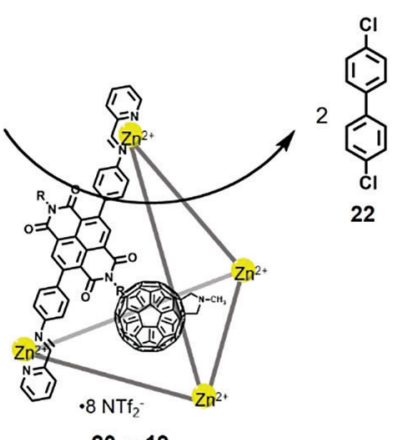

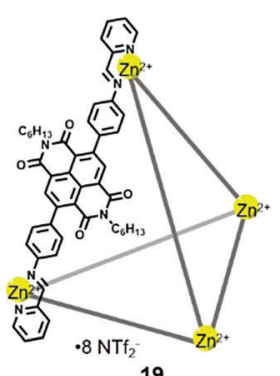

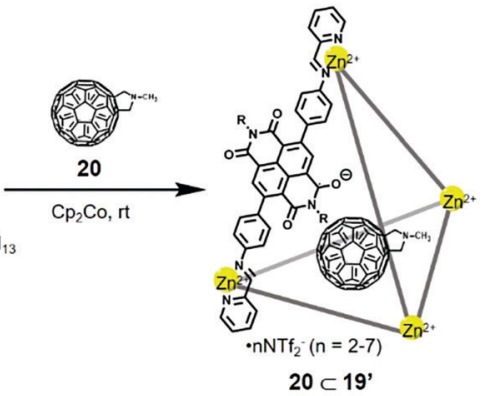

$20 \subset 19$ '

Fig. 5 (a) Synthesis of NDI-based tetrahedral cage 19. (b) Host-guest complexation of cage 19 with 20 and the subsequent reduction with $\mathrm{Cp}_{2} \mathrm{Co}$. (c) Transferred tetrakis(4-chlorophenyl)borate 21 into 4,4'dichlorobiphenyl 22 with the catalysis of complex $20 \subset 19$.

was similar to the analogous polyaromatic cages. ${ }^{1 n}$ Thus, interestingly, the reduced form of cage $\mathbf{2 4}$ showed obvious affinity for $\mathrm{C}_{60}$, probably due to the partially neutralized charges upon reduction (Fig. 6c). Further addition of $\mathrm{AgNTf}_{2}$ into the complex led to the release of $\mathrm{C}_{60}$, which required more than 30 days due to the kinetically trapped nature of the complex. Moreover, when the $\mathbf{C}_{\mathbf{6 0}} \subset \mathbf{2 4}$ complex was treated in MeCN/EtOAc (1:1) with aqueous $\mathrm{Na}_{2} \mathrm{SO}_{4}$, cage 24 was transferred into the water phase, and $\mathrm{C}_{60}$ was released, which could be applied in chemical purification due to its simplicity and recyclability. In conclusion, this research realized redoxswitchable guest uptake and release behaviour within an NDI cage, which could be helpful for designing supramolecular systems for chemical separations and transport.

In 2018, Chand and co-workers reported the preparation of an NDI-based $\mathrm{Pd}_{2} \mathrm{~L}_{4}$-type metal-organic cage, which can form metallogels with multi-stimulus-responsive properties and anionic dye removal ability. ${ }^{18}$ As shown in Fig. 7, NDI-containing 


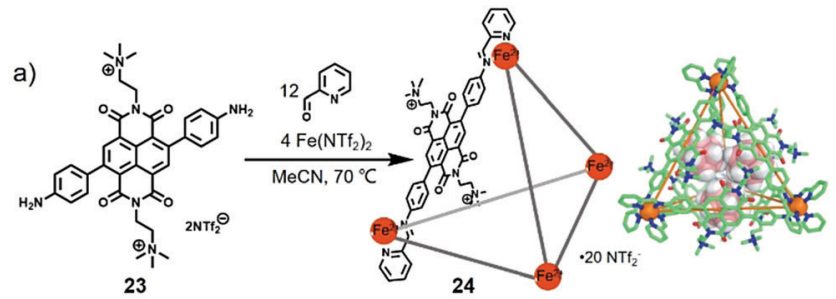

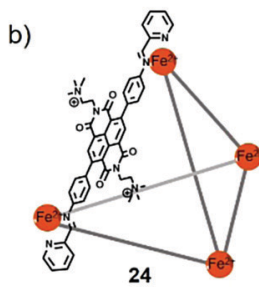
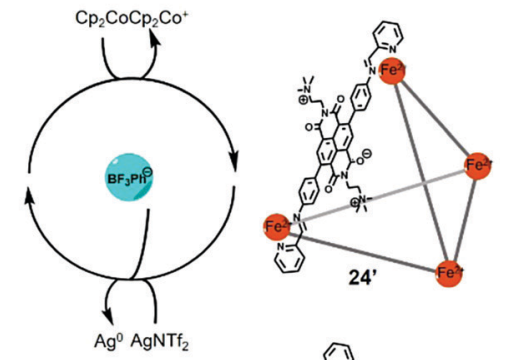

c)

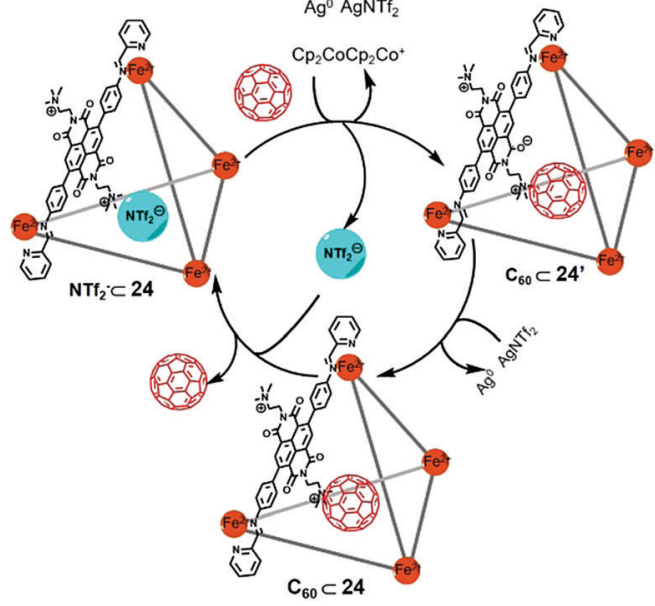

Fig. 6 (a) Synthesis of NDI-based tetrahedral cage 24 and its crystal structure. (b) Redox control of $\mathrm{KBF}_{3} \mathrm{Ph}$ binding within 24. (c) The encapsulation and release of $\mathrm{C}_{60}$ within cage 24 upon reduction with $\mathrm{Cp}_{2} \mathrm{Co}$ and subsequent re-oxidation with $\mathrm{AgNTf}_{2}$. Reproduced from ref. 17 with permission from Royal Society of Chemistry, copyright 2020.

ligand 25 reacted with $\mathrm{Pd}\left(\mathrm{NO}_{3}\right)_{2}$ in DMSO or $\mathrm{MeCN} / \mathrm{H}_{2} \mathrm{O}$ to afford cylindrical-drum-shaped NDI cage 26. Interestingly, adding cage 26 in DMSO or $\mathrm{MeCN} / \mathrm{H}_{2} \mathrm{O}$ led to the formation of gels, and the concentration, solvent, counteranion and metal ions had a considerable impact on the formation of gels. UV-Vis spectral studies showed a hyperchromic shift with increasing concentrations, probably due to the aggregation of cage 26 in solution. Rheology studies confirmed the formation of gels and revealed that the strength of the gel increased with increasing temperature or concentration. In addition, the gel also exhibited multistimulus-responsive properties including a thixotropic nature and chemical-stimulus-responsive behaviour. For example, upon vigorous shaking or addition of TBABr or DMAP, the metallogel changed into a solution state and could be recovered upon subsequent standing or addition of $\mathrm{AgNO}_{3}$ or $\mathrm{TsOH}$, indicating that the stimulus-responsive property was reversible (Fig. 7b). Moreover, UV-Vis spectral experiments indicated that the gel could uptake pyrene due to the electron-deficient nature of the NDI ligand and the suitable cavity of the cage. a)
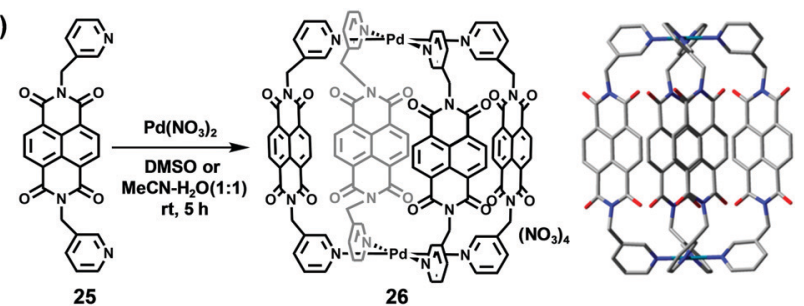

b)

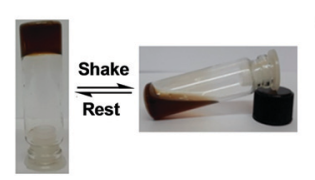

c)
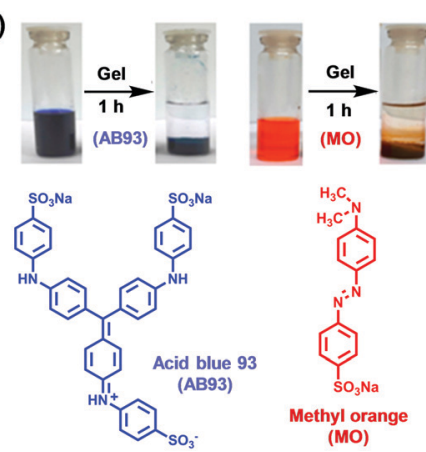

Fig. 7 (a) Synthesis of NDI-based cage 26 and its optimized structure. (b) Stimulus-responsive behaviour of the metallogel upon shaking/resting and the addition of $\mathrm{TBABr} / \mathrm{AgNO}_{3}$ or $\mathrm{DMAP} / \mathrm{TsOH}$ pairs. (c) Removal of anion dyes $A B 93$ and $M O$ with the metallogel. Reproduced from ref. 18 with permission from American Chemical Society, copyright 2018.

Furthermore, as shown in Fig. 7c, the gel could be used for dye removal, and the results showed that the gel could efficiently remove anionic dyes instead of cationic dyes due to the positive charge character of the NDI cage.

\section{Perylene diimide-based cages}

Relative to the NDI derivatives, perylene diimide (PDI) derivatives have a larger planar structure and $\pi$-conjugation and intense absorption in the visible region. In general, PDI derivatives exhibit two reversible one-electron reduction with half-wave potentials of $-0.96 \mathrm{~V}$ and $-1.22 \mathrm{~V}$ vs. $\mathrm{Fc} / \mathrm{Fc}^{+}$in $\mathrm{CH}_{2} \mathrm{Cl}_{2} \cdot{ }^{6 d}$ Compared with a large number of reported PDI-based macrocycles, ${ }^{8}$ PDI-based cages have rarely been investigated. Herein, we introduce some PDI-based cages, including metalcoordinated and covalent cages, and the photochemical and electrochemical properties of the cages as well as their applications in molecular sensing and photocatalysis.

Würthner and co-workers reported several PDI-based metalorganic cages. In 2013, they reported the preparation of giant tetrahedral PDI cages and investigated their photo- and electrochemical properties and host-guest behaviour. ${ }^{19}$ As shown in Fig. 8, treatment of the bipyridine-functionalized PDI ligand 27 with $\mathrm{FeX}_{2}\left(\mathrm{X}=\mathrm{BF}^{4-}\right.$, OTf $\left.{ }^{-}\right)$in a solution of $\mathrm{CH}_{3} \mathrm{CN} / \mathrm{CHCl}_{3}(1: 1)$ provided tetrahedral cages 28-29. The cages were well characterized by ${ }^{1} \mathrm{H}$ NMR, 2D DOSY and ESI-MS spectra. Furthermore, UV-vis spectroscopy and cyclic voltammetry (CV) were performed to investigate the photo- and electrochemical properties of the cages. UV-Vis spectral studies indicated that cages 28-29 exhibited two main absorption bands at 542 and $580 \mathrm{~nm}$ in the visible region (corresponding to the PDI subunits) with molar 
a)

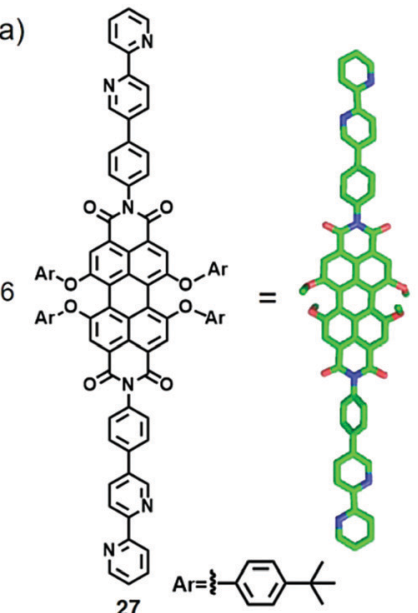

b)

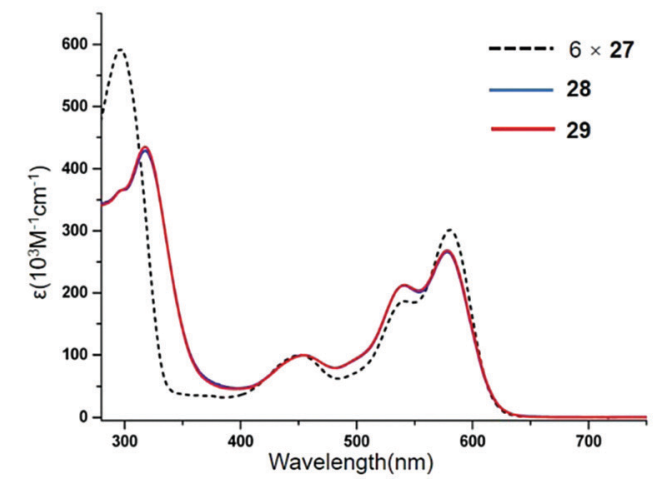

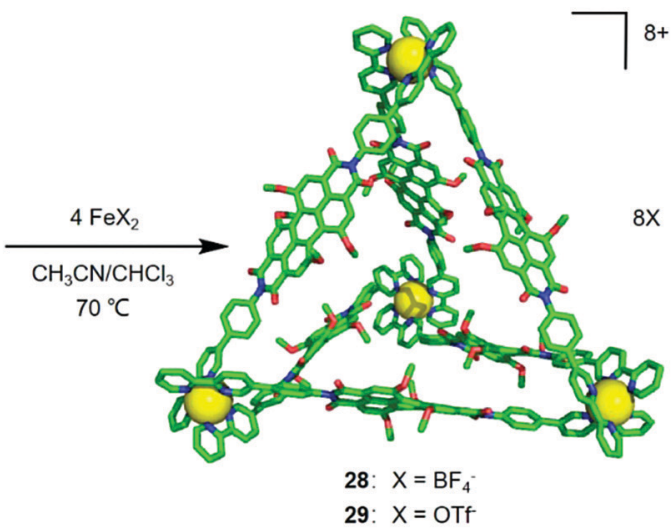

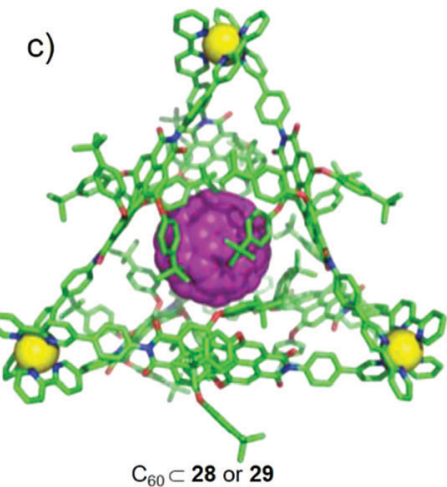

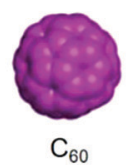

$3 x$
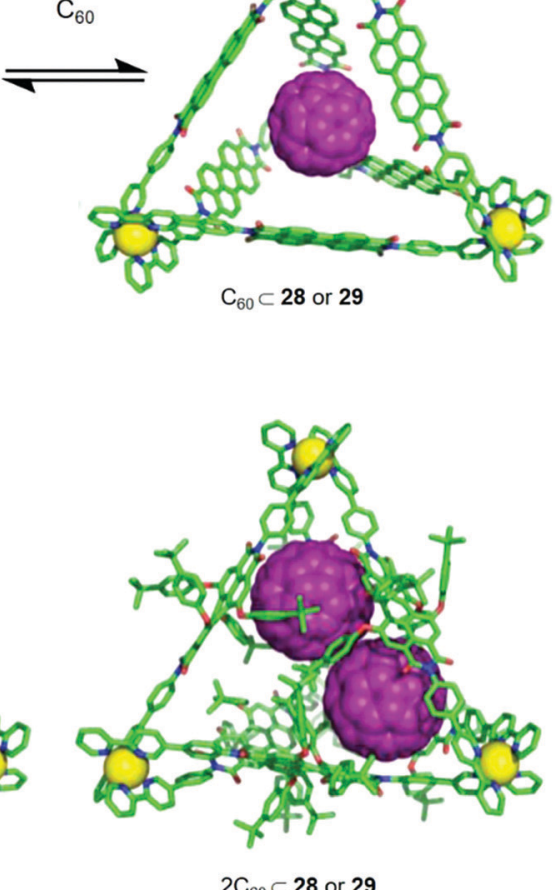

Fig. 8 (a) Synthesis of PDI-based tetrahedral cages 28-29 and graphical representation of the complexation of 28-29 with $\mathrm{C}_{60}$. (b) UV-Vis absorption spectrum of $\mathbf{2 7 - 2 9}$. (c) Optimized structure of $\mathbf{C}_{\mathbf{6 0}} \subset \mathbf{2 8}$ or $\mathbf{2 9}$ and $\mathbf{2 C}_{\mathbf{6 0}} \subset \mathbf{2 8}$ or $\mathbf{2 9}$. Reproduced from ref. 19 with permission from American Chemical Society, copyright 2013.

absorption coefficients of 212700 and $268500 \mathrm{M}^{-1} \mathrm{~cm}^{-1}$, respectively, almost six times as high as the PDI ligand 27 . In addition, the peak of the bipyridine units at $297 \mathrm{~nm}$ showed a redshift of approximately $20 \mathrm{~nm}$, and the relative intensities of the peaks at 542 and $580 \mathrm{~nm}$ also varied due to the metalto-ligand charge-transfer of $\left[\mathrm{Fe}(\text { bipyridine })_{3}\right]^{2+}$ complexes (Fig. 8b). CV experiments indicated that the cages showed two reversible oxidation waves at $0.95\left(\mathrm{PBI} / \mathrm{PBI}^{+}\right)$and $0.73 \mathrm{~V}$ $\left(\mathrm{Fe}^{2+} / \mathrm{Fe}^{3+}\right)$ vs. $\mathrm{Fc} / \mathrm{Fc}^{+}$and five reversible reduction waves at $-0.94\left(\mathrm{PBI} / \mathrm{PBI}^{-}\right),-1.11\left(\mathrm{PBI}^{-} / \mathrm{PBI}^{2-}\right),-1.65,-1.84$ and $-2.08 \mathrm{~V}\left(\mathrm{bpy} / \mathrm{bpy}^{-}\right) v s . \mathrm{Fc} / \mathrm{Fc}^{+}$. The higher oxidation potential of $\mathrm{Fe}^{2+} / \mathrm{Fe}^{3+}$ was probably due to the $\mathrm{Fe}^{2+}$ metal centre being close to the electron-deficient PDI moieties, and the easier reduction of cage $\mathbf{2 8}$ could be ascribed to the preorganized framework and highly porous nature of the PDI cage. In addition, the counteranions $\left(\mathrm{BF}^{4-}\right.$ or $\left.\mathrm{OTf}^{-}\right)$had a negligible influence on the photo- and electrochemical properties of the cages. Moreover, the results of ${ }^{13} \mathrm{C}$ NMR and ESI-TOF-MS spectra indicated that the cage could efficiently encapsulate $\mathrm{C}_{60}$, and the UV-Vis absorption spectra suggested that each cage bound $1.9 \mathrm{C}_{60}$ on average. Considering the volume of $\mathrm{C}_{60}$ $\left(597 \AA^{3}\right)$ and the PDI cage (950-2150 $\AA^{3}$ due to the rotatable $\mathrm{OPh}^{t} \mathrm{Bu}$ substituents), the host-guest behaviour of the cage is consistent with the principle of the empirical $55 \%$ rule established by Mecozzi and Rebek. ${ }^{20}$ Additionally, the results of molecular stimulations indicated that when the cage bound one $\mathrm{C}_{60}, \mathrm{C}_{60}$ was located in almost the centre of the cavity, and there was no interaction between the cage and $\mathrm{C}_{60}$ (Fig. 8c). However, when the cage bound two $\mathrm{C}_{60}$, the guests were located in the corner of the cage to afford enough space for binding both guests. Notably, $\mathbf{2 8}$ or $\mathbf{2 9}$ displayed the ability of binding two $\mathrm{C}_{60}$ in one cage, which was different from the common polyaromatic cages ${ }^{1 n}$ that could only bind one $\mathrm{C}_{60}$, probably due to its larger internal cavity. This research successfully constructed PDI cages with affinity for $\mathrm{C}_{60}$, which afforded a guideline for designing functional cages for guest encapsulation and reaction within the cavity.

Even though PDI cages 28-29 showed efficient bonding with $\mathrm{C}_{60}$, the cages were non-emissive because the coordinated $\mathrm{Fe}$ metal atom facilitated intersystem crossing (ISC) and subsequent non-radiative decay, which hampered their fluorescence sensing. ${ }^{21}$ Hence, Würthner and co-workers reported the synthesis of a highly fluorescent tetrahedral PDI cage and studied its host-guest behaviour in $2015 .^{22}$ As shown in Fig. 9, the reaction of PDI-containing ligand 30, $\mathrm{Zn}\left(\mathrm{NTf}_{2}\right)_{2}$ and tris(2-aminoethyl)amine (TREN) under microwave heating at $100{ }^{\circ} \mathrm{C}$ provided tetrahedral PDI cage 31 in $92 \%$ yield. It should be noted that $\mathrm{Zn}$ was vital for the formation of the fluorescent cage. Cage 31 
a)

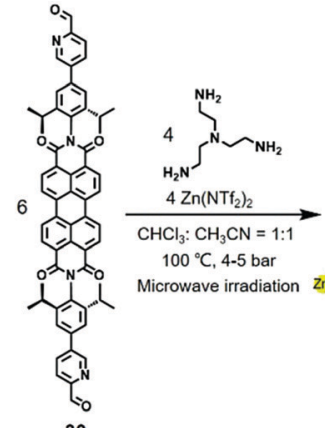

d)

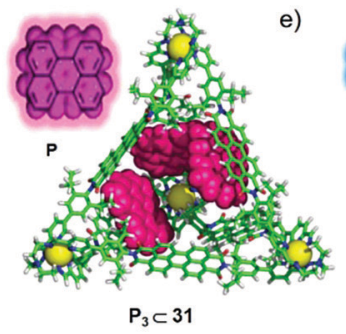

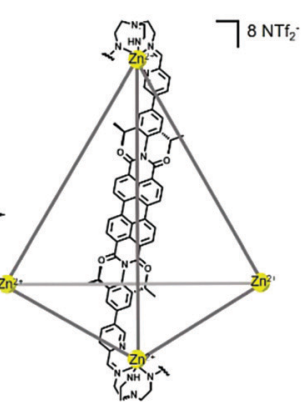

31

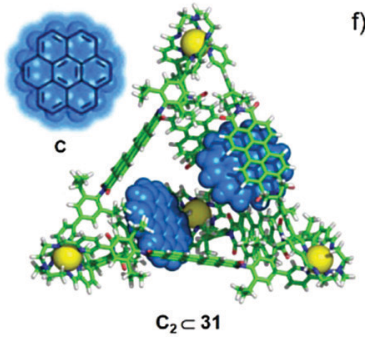

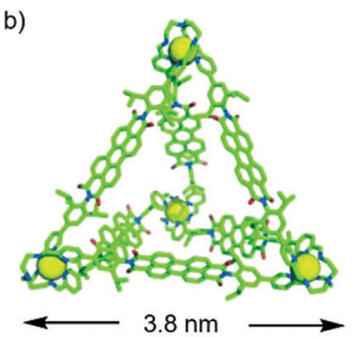

f)

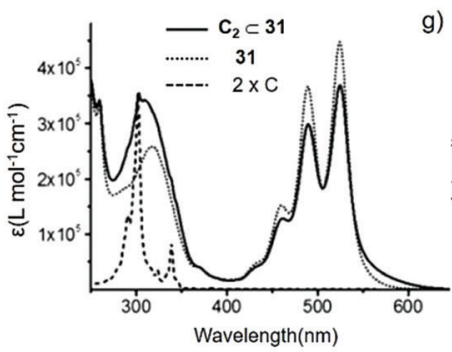

c)

g)
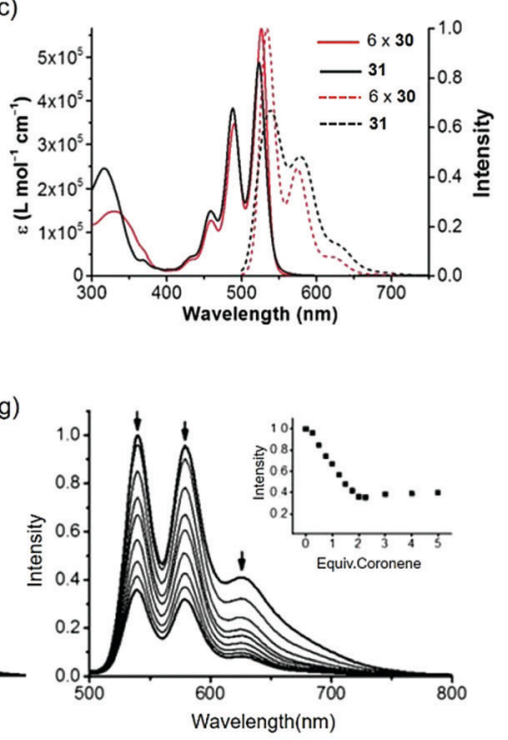

Fig. 9 (a) Synthesis of PDI-based tetrahedral cage 31. (b) Optimized structure of cage 31. (c) Absorption and emission spectra of $\mathbf{3 0}$ and $\mathbf{3 1}$ in $\mathrm{CH}_{3} \mathrm{CN}$ $\left(\lambda_{\mathrm{ex}}=490 \mathrm{~nm}\right)$. (d) Optimized structure of the host-guest complex $\mathbf{P}_{\mathbf{3}} \subset \mathbf{3 1}$ ( $\mathrm{P}=$ perylene). (e) Optimized structure of the host-guest complex $\mathbf{C}_{\mathbf{2}} \subset \mathbf{3 1}$ ( $C=$ coronene). (f) Absorption spectrum of $\mathbf{3 1}, \mathbf{C}$ and $\mathbf{C}_{\mathbf{2}} \subset \mathbf{3 1}$. (g) Emission spectra upon the addition of $\mathbf{C}$ into 31 . Reproduced from ref. 22 with permission from Wiley-VCH, copyright 2015.

was well characterized by ${ }^{1} \mathrm{H}$ NMR, 2D NMR and ESI-MS spectra. Variable-temperature ${ }^{1} \mathrm{H}$ NMR experiments showed a diastereomeric ratio of $1: 0.9: 0.7$ for the $T, S_{4}$, and $C_{3}$ diastereomers of the cage. 2D DOSY NMR indicated that the hydrodynamic radius of cage 31 was $2.2 \mathrm{~nm}$, in good agreement with the result from theoretical simulations $(1.9 \mathrm{~nm})$. In addition, the results of the MMFF geometry optimization model indicated that the length of the edge of cage $\mathbf{3 1}$ was $3.8 \mathrm{~nm}$ and the internal volume was approximately $1300 \AA^{3}$ (Fig. 9b). Further investigations on the photophysical properties revealed that $\mathbf{3 1}$ showed two main absorption bands at $488 \mathrm{~nm}$ and $523 \mathrm{~nm}$ corresponding to the absorption of PDI units and two emission peaks at 538 and
$578 \mathrm{~nm}$ with a quantum yield of $0.67 \pm 0.02$ (Fig. 9c). The decrease in the quantum yield relative to that of the PDI ligand (almost unity) was probably due to excitonic coupling between the adjacent PDI chromophore. The fluorescence lifetime of cage $\mathbf{3 1}$ was also calculated and determined to be $4.8 \mathrm{~ns}$. Furthermore, the hostguest behaviour of the cage was studied, and ${ }^{1} \mathrm{H}$ NMR titrations indicated that cage 31 could form a 1:3 complex with perylene or a $1: 2$ complex with coronene (Fig. 9d and e). Furthermore, the hostguest complexation induced a decrease in the absorption and emission intensity of $\mathbf{3 1}$, probably due to the photoinduced charge transfer from the PDI units to the guests (Fig. 9f and g). In addition, the phenomenon of amplified emission quenching
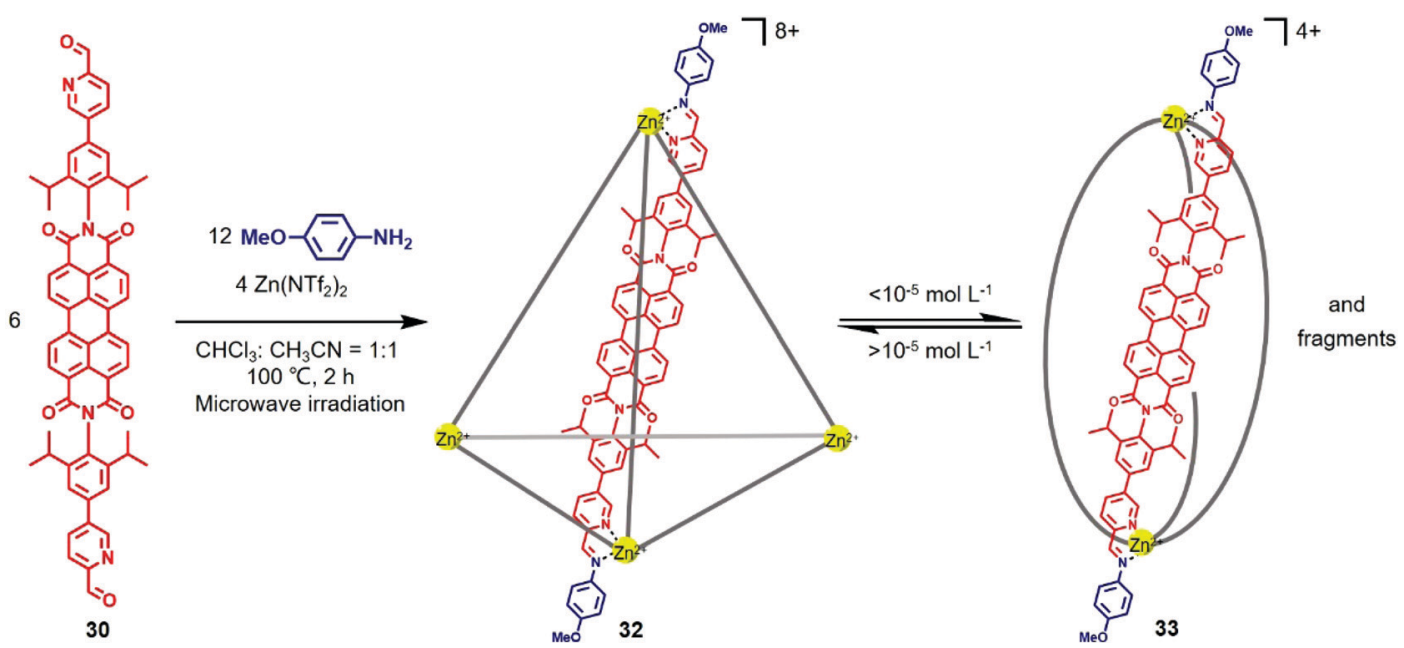

Fig. 10 Synthesis of PDI-based tetrahedral cage 32 and its concentration-dependent supramolecular transformation. 
(one guest caused the quenching of 2.1 PBI units) could be ascribed to the close contact of the cage and guests. In conclusion, this work realized fluorescence sensing based on a highly emissive PDI cage, which laid the foundation for constructing fluorescent self-assembly hosts for molecular recognition.

Similarly, in 2015, Würthner and co-workers reported the synthesis of a large PDI-based tetrahedron and investigated its supramolecular transformation at various concentrations. ${ }^{23}$ As shown in Fig. 10, PDI cage 32 was obtained via subcomponent self-assembly of PDI-containing ligand 30, $p$-anisidine with $\mathrm{Zn}\left(\mathrm{NTf}_{2}\right)_{2}$ under microwave conditions at $100{ }^{\circ} \mathrm{C}$. The NMR, ESI-MS and atomic force microscopy (AFM) results confirmed the formation of the $\mathrm{M}_{4} \mathrm{~L}_{6}$-type tetrahedral cage. However, the concentration had a great influence on the structure of the self-assembly product. ${ }^{1} \mathrm{H}$ NMR and UV/Vis spectral studies indicated that the initial $\mathrm{M}_{4} \mathrm{~L}_{6}$ tetrahedron disassembles into an $\mathrm{M}_{2} \mathrm{~L}_{3}$-type helicate with some fragments when the concentration was below $8.7 \times 10^{-6} \mathrm{~mol} \mathrm{~L}^{-1}$. In addition, similar to $\mathbf{3 1}$, the cage also showed fluorescence upon $\mathrm{Zn}$ coordination.

In 2019, Zhang et al. reported the preparation of chiral imine cages based on PDI and investigated their host-guest and photocatalytic behaviour. ${ }^{24}$ As shown in Fig. 11, treatment of PDI-containing diamine $34(R$ or $S)$ and tetraphenylethene (TPE)-containing tetraaldehyde 35 provided PDI-TPE cage 36 $\left(R\right.$ or $S$ ). The cages were well characterized by ${ }^{1} \mathrm{H}$ NMR, 2D NMR and ESI-MS spectra. Circular dichroism (CD) spectra of the two cages displayed signals with complete mirror symmetry, demonstrating that the cages were enantiomeric. UV-Vis absorption of cage $\mathbf{R}-\mathbf{3 6}$ exhibited a maximum absorption peak at $526 \mathrm{~nm}$, consistent with the PDI ligand, revealing no interaction between the PDI units in the cage. The fluorescence spectra of cage R-36 indicated that J-type aggregation occurred at higher concentrations resulting from charge transfer between TPE and PDI units. In addition, CV experiments of the cage showed two reduction peaks at $-0.84 \mathrm{~V}$ and $-1.05 \mathrm{~V}$ (vs. SCE), which were assigned to the formation of $\mathrm{PDI}^{*^{-}}$and $\mathrm{PDI}^{2-}$, respectively. Furthermore, the host-guest behaviour of cages with polycyclic aromatic hydrocarbons (PAHs), such as perylene and naphthalene, was investigated. The fluorescence of the guests declined dramatically upon the addition of cage R-36, probably due to the aromatic $\pi-\pi$ stacking interaction between the planar PAHs and PDI subunits (Fig. 11c). Fluorescence titration experiments indicated that the cage could bind 18-22 small PAH molecules, such as naphthalene and pyrene, or 8-10 larger PAH molecules, such as perylene and 9,10-diphenylanthracene. In addition, the fluorescence of the cage itself was enhanced upon guest binding because a large number of guests occupied the space of the cage and decreased the structural relaxation of the PDI units. Since cage $\mathbf{R}-\mathbf{3 6}$ had strong absorption in the visible range and could efficiently encapsulate a series of guest molecules, it could further serve as a visible-light photocatalyst. The results indicated that cage R-36 could efficiently transform 2-aryloxybenzoic acids $\mathbf{3 7}$ into aryl salicylates 38 (Smiles rearrangement) under a blue LED (Fig. 11d). The higher catalytic efficiency of the cage relative to a)

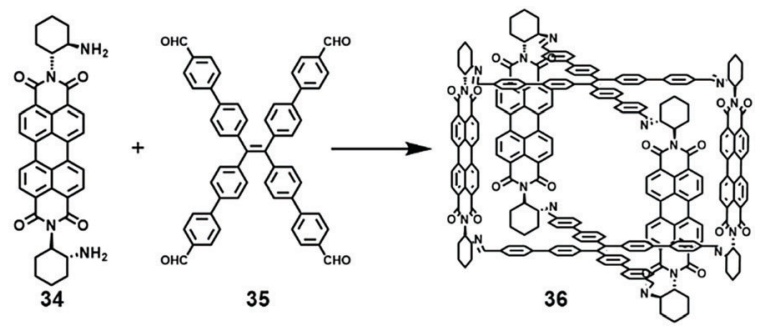

b)

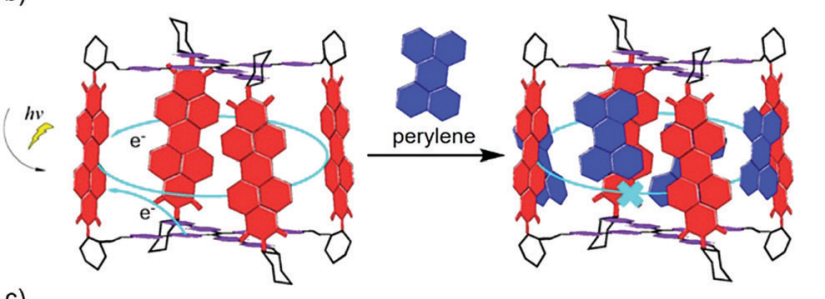

c)

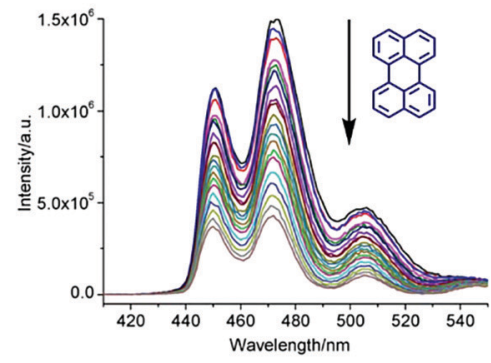

d)

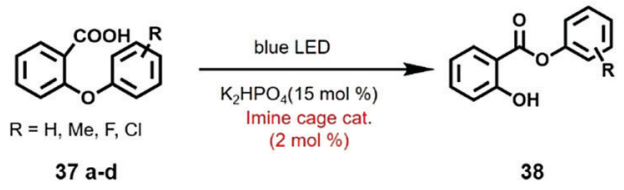

Fig. 11 (a) Synthesis of PDI-based imine cage 36 from PDI-containing diamine 34 and TPE-containing tetraaldehyde 35. (b) The host-guest behaviour of cage R-36 with perylene. (c) Emission spectrum of perylene following the titration of R-36. (d) Smiles rearrangement under the photolysis of cage R-36. Reproduced from ref. 24 with permission from Wiley-VCH, copyright 2019

the PDI ligand was ascribed to intermolecular photoinduced electron transfer from TPE to PDI units, indicating the importance of the existence of the imine cage. Moreover, different substituents on the substrate had an important effect on the catalytic activity, and an electron-donating group in the ortho position in 37 could improve the yield. In conclusion, this research constructed a PDI-based imine cage for visible-light photocatalysis, affording a guideline for designing photoactive supramolecular hosts for photochemical reactions.

\section{Conclusions}

NDI-/PDI-based cages, including metal coordination and dynamic covalent cages, which possess different properties and functions, have been investigated during the past few years. First, due to the planar structure and electron-deficient nature of NDI/PDI, the cages could bind various electron-rich guests, which were further applied in molecular sensing and constructing a dynamic combinatorial library (DCL). Second, the cages 
with redox-switchable properties resulting from NDI/PDI units showed unique functions, including controllable uptake and release and catalysis for $\mathrm{C}-\mathrm{C}$ bond coupling. In addition, the NDI/PDI cages could also be applied in dye removal or photocatalysis, indicating their large potential. Even so, there are still some issues that need to be addressed in this field. For example, the types of catalytic reaction of the NDI/PDI cages are very limited. On the other hand, due to the utilization of $\mathrm{Fe}^{2+}$ as vertices for constructing metal coordination cages, most of the NDI/PDI cages were non-fluorescent even though NDI/PDI ligands were highly emissive, which hampered their development of fluorescent materials.

Thus, in our view, some improvement should be taken into consideration in further developing NDI/PDI cages. On one hand, NDI/PDI ligands should be designed reasonably. According to some unpublished results in our group, we could make use of NDI/PDI ligands with larger $\pi$-conjugation to construct cages that bind more sophisticated guests, thus further extending their catalytic reactions. On the other hand, more kinds of metals should be utilized to construct cages with various shapes and topological architectures. This may not only prevent the fluorescence quenching of NDI/PDI ligands to some extent but also extend their applications, such as photocatalysis. In conclusion, NDI-/PDI-based cages will be considered to play more important roles in a wide range of fields, including supramolecular chemistry and materials science, in the future.

\section{Conflicts of interest}

There are no conflicts to declare.

\section{Acknowledgements}

This work was supported by the National Nature Science Foundation of China (No. 21922506, 21871092, and 21672070), the Fundamental Research Funds for the Central Universities, the Opening Projects of Shanghai Key Laboratory of Green Chemistry and Chemical Processes, and State Key Laboratory of Fine Chemicals (KF 1801).

\section{Notes and references}

1 (a) J.-M. Lehn, Cryptates: inclusion complexes of macropolycyclic receptor molecules, Pure Appl. Chem., 1978, 50, 871-892; (b) S. Tashiro and M. Shionoya, Novel Porous Crystals with Macrocycle-Based Well-Defined Molecular Recognition Sites, Acc. Chem. Res., 2020, 53, 632-643; (c) X. Ji, M. Ahmed, L. Long, N. M. Khashab, F. Huang and J. L. Sessler, Adhesive supramolecular polymeric materials constructed from macrocycle-based host-guest interactions, Chem. Soc. Rev., 2019, 48, 2682-2697; (d) P. S. Bols and H. L. Anderson, Template-Directed Synthesis of Molecular Nanorings and Cages, Acc. Chem. Res., 2018, 51, 2083-2092; (e) Y. Jin, Q. Wang, P. Taynton and W. Zhang,
Dynamic Covalent Chemistry Approaches Toward Macrocycles, Molecular Cages, and Polymers, Acc. Chem. Res., 2014, 47, 1575-1586; $(f)$ A. J. McConnell, C. S. Wood, P. P. Neelakandan and J. R. Nitschke, Stimuli-Responsive Metal-Ligand Assemblies, Chem. Rev., 2015, 115, 7729-7793; (g) M.-X. Wang, Nitrogen and Oxygen Bridged Calixaromatics: Synthesis, Structure, Functionalization, and Molecular Recognition, Acc. Chem. Res., 2012, 45, 182-195; (h) M. Yoshizawa and L. Catti, Bent Anthracene Dimers as Versatile Building Blocks for Supramolecular Capsules, Acc. Chem. Res., 2019, 52, 2392-2404; ( $i$ K. K. Acharyya and P. S. Mukherjee, Organic Imine Cages: Molecular Marriage and Applications, Angew. Chem., Int. Ed., 2019, 58, 8640-8653; ( $j$ ) F. Würthner, C.-C. You and C. R. Saha-Möller, Metallosupramolecular squares: from structure to function, Chem. Soc. Rev., 2004, 33, 133-146; (k) W.-X. Gao, H.-N. Zhang and G.-X. Jin, Supramolecular catalysis based on discrete heterometallic coordinationdriven metallacycles and metallacages, Coord. Chem. Rev., 2019, 386, 69-84; ( $l$ ) H. Zhu, L. Shangguan, B. Shi, G. Yu and F. Huang, Recent progress in macrocyclic amphiphiles and macrocyclic host-based supra-amphiphiles, Mater. Chem. Front., 2018, 2, 2152-2174; ( $m$ ) Y. Qin, X. Liu, P.-P. Jia, L. Xu and H.-B. Yang, BODIPY-based macrocycles, Chem. Soc. Rev., 2020, 49, 5678-5703; (n) M. Yoshizawa and M. Yamashina, Coordination-driven Nanostructures with Polyaromatic Shells, Chem. Lett., 2017, 46, 163-171; (o) K. Yazaki, L. Catti and M. Yoshizawa, Polyaromatic molecular tubes: from strategic synthesis to host functions, Chem. Commun., 2018, 54, 3195-3206.

2 (a) T. Kakuta, T.-A. Yamagishi and T. Ogoshi, Stimuliresponsive supramolecular assemblies constructed from pillar[n]arenes, Acc. Chem. Res., 2018, 51, 1656-1666; (b) H. Zhu, J. Liu, B. Shi, H. Wang, Z. Mao, T. Shan and F. Huang, Pillararene-based host-guest recognition facilitated magnetic separation and enrichment of cell membrane proteins, Mater. Chem. Front., 2018, 2, 1475-1480; (c) Z. Zhang, K. Sun, S. Li and G. Yu, A pillar[5]arene-based molecular grapple of hexafluorophosphate, Chin. Chem. Lett., 2019, 30, 957-960.

3 (a) M. Fujita, M. Tominaga, A. Hori and B. Therrien, Coordination assemblies from a Pd(II)-cornered square complex, Acc. Chem. Res., 2005, 38, 369-378; (b) L.-J. Chen, H.-B. Yang and M. Shionoya, Chiral metallosupramolecular architectures, Chem. Soc. Rev., 2017, 46, 2555-2576; (c) Z. Zhang, Y. Li, B. Song, Y. Zhang, X. Jiang, M. Wang, R. Tumbleson, C. Liu, P. Wang, X.-Q. Hao, T. Rojas, A. T. Ngo, J. L. Sessler, G. R. Newkome, S. W. Hla and X. Li, Intra- and intermolecular self-assembly of a $20 \mathrm{~nm}$-wide supramolecular hexagonal grid, Nat. Chem., 2020, 12, 468-474; (d) J. Zhu, X. Liu, J. Huang and L. Xu, Our expedition in the construction of fluorescent supramolecular metallacycles, Chin. Chem. Lett., 2019, 30, 1767-1774; (e) Y.-X. Hu, X. Hao, L. Xu, X. Xie, B. Xiong, Z. Hu, H. Sun, G.-Q. Yin, X. Li, H. Peng and H.-B. Yang, Construction of Supramolecular Liquid-Crystalline Metallacycles for Holographic Storage of Colored Images, J. Am. Chem. Soc., 2020, 142, 6285-6294; (f) J.-L. Zhu, L. Xu, 
Y.-Y. Ren, Y. Zhang, X. Liu, G.-Q. Yin, B. Sun, X. Cao, Z. Chen, X.-L. Zhao, H. Tan, J. Chen, X. Li and H.-B. Yang, Switchable Organoplatinum Metallacycles with High Quantum Yields and Tunable Fluorescence Wavelengths, Nat. Commun., 2019, 10, 4285; $(g)$ M. L. Saha, X. Yan and P. J. Stang, Photophysical Properties of Organoplatinum(II) Compounds and Derived Self-Assembled Metallacycles and Metallacages: Fluorescence and its Applications, Acc. Chem. Res., 2016, 49, 2527-2539; (h) C.-B. Huang, L. Xu, J.-L. Zhu, Y.-X. Wang, B. Sun, X. Li and H.-B. Yang, Real-Time Monitoring the Dynamics of Coordination-Driven Self-Assembly by Fluorescence-Resonance Energy Transfer, J. Am. Chem. Soc., 2017, 139, 9459-9462; ( $i$ ) L. Ma, T. Yang, Z. Zhang, S. Yin, Z. Song, W. Shi, D. Chu, Y. Zhang and M. Zhang, Cyanostilbene-based near-infrared emissive platinum(II) metallacycles for cancer theranostics, Chin. Chem. Lett., 2019, 30, 1942-1946.

4 (a) S. Pullen and G. H. Clever, Mixed-ligand metal-organic frameworks and heteroleptic coordination cages as multifunctional scaffolds-a comparison, Acc. Chem. Res., 2018, 51, 3052-3064; (b) A. M. Castilla, W. J. Ramsay and J. R. Nitschke, Stereochemistry in subcomponent self-assembly, Acc. Chem. Res., 2014, 47, 2063-2073; (c) L.-X. Cai, S.-C. Li, D.-N. Yan, L.-P. Zhou, F. Guo and Q.-F. Sun, Water-Soluble Redox-Active Cage Hosting Polyoxometalates for Selective Desulfurization Catalysis, J. Am. Chem. Soc., 2018, 140, 4869-4876; (d) X. Zhang, X. Dong, W. Lu, D. Luo, X.-W. Zhu, X. Li, X.-P. Zhou and D. Li, Fine-Tuning Apertures of Metal-Organic Cages: Encapsulation of Carbon Dioxide in Solution and Solid State, J. Am. Chem. Soc., 2019, 141, 11621-11627; (e) J. Guo, Y.-Z. Fan, Y.-L. Lu, S.-P. Zheng and C.-Y. Su, Visible-Light Photocatalysis of Asymmetric $[2+2]$ Cycloaddition in Cage-Confined Nanospace Merging Chirality with Triplet-State Photosensitization, Angew. Chem., Int. Ed., 2020, 59, 8661-8669; $(f)$ J. Wei, L. Zhao, C. He, S. Zheng, J. N. H. Reek and C. Duan, Metal-Organic Capsules with NADH Mimics as Switchable Selectivity Regulators for Photocatalytic Transfer Hydrogenation, J. Am. Chem. Soc., 2019, 141, 12707-12716; (g) L. Xu, D. Zhang, T. K. Ronson and J. R. Nitschke, Improved Acid Resistance of a Metal-Organic Cage Enables Cargo Release and Exchange between Hosts, Angew. Chem., Int. Ed., 2020, 59, 7435-7438; (h) L. Zhang, R. Das, C.-T. Li, Y.-Y. Wang, F. E. Hahn, K. Hua, L.-Y. Sun and Y.-F. Han, $C_{3}$-Symmetric Assemblies from Trigonal Polycarbene Ligands and MI Ions for the Synthesis of Three-Dimensional Polyimidazolium Cations, Angew. Chem., Int. Ed., 2019, 58, 13360-13364.

5 (a) W. Cullen, M. C. Misuraca, C. A. Hunter, N. H. Williams and M. D. Ward, Highly efficient catalysis of the Kemp elimination in the cavity of a cubic coordination cage, Nat. Chem., 2016, 8, 231-236; (b) P. Howlader, B. Mondal, P. C. Purba, E. Zangrando and P. S. Mukherjee, Selfassembled Pd(II) barrels as containers for transient merocyanine form and reverse thermochromism of spiropyran,
J. Am. Chem. Soc., 2018, 140, 7952-7960; (c) D. Fujita, Y. Ueda, S. Sato, N. Mizuno, T. Kumasaka and M. Fujita, Self-assembly of tetravalent Goldberg polyhedra from 144 small components, Nature, 2016, 540, 563-566; (d) Q.-Q. Wang, S. Gonell, S. H. A. M. Leenders, M. Dürr, I. IvanovićBurmazović and J. N. H. Reek, Self-assembled nanospheres with multiple endohedral binding sites pre-organize catalysts and substrates for highly efficient reactions, Nat. Chem., 2016, 8, 225-230; (e) M. Yamashina, Y. Tanaka, R. Lavendomme, T. K. Ronson, M. Pittelkow and J. R. Nitschke, An antiaromatic-walled nanospace, Nature, 2019, 574, 511-515; $(f)$ K. Li, L.-Y. Zhang, C. Yan, S.-C. Wei, M. Pan, L. Zhang and C.-Y. Su, Stepwise assembly of $\operatorname{Pd}_{6}\left(\mathrm{RuL}_{3}\right)_{8}$ nanoscale rhombododecahedral metal-organic cages via metalloligand strategy for guest trapping and protection, J. Am. Chem. Soc., 2014, 136, 4456-4459; (g) L. Catti, N. Kishida, T. Kai, M. Akita and M. Yoshizawa, Polyaromatic nanocapsules as photoresponsive hosts in water, Nat. Commun., 2019, 10, 1948; (h) H. Duan, Y. Li, Q. Li, P. Wang, X. Liu, L. Cheng, Y. Yu and L. Cao, Host-Guest Recognition and Fluorescence of a TetraphenyletheneBased Octacationic Cage, Angew. Chem., Int. Ed., 2020, 59, 10101-10110; (i) Z. Sun, P. Li, S. Xu, Z.-Y. Li, Y. Nomura, Z. Li, X. Liu and S. Zhang, Controlled Hierarchical SelfAssembly of Catenated Cages, J. Am. Chem. Soc., 2020, 142, 10833-10840; ( $j$ ) Z. Zhang, Z. Zhao, L. Wu, S. Lu, S. Ling, G. Li, L. Xu, L. Ma, Y. Hou, X. Wang, X. Li, G. He, K. Wang, B. Zou and M. Zhang, Emissive Platinum(II) Cages with Reverse Fluorescence Resonance Energy Transfer for Multiple Sensing, J. Am. Chem. Soc., 2020, 142, 2592-2600; (k) D. Zhang, T. K. Ronson, L. Xu and J. R. Nitschke, Transformation Network Culminating in a Heteroleptic $\mathrm{Cd}_{6} \mathrm{~L}_{6} \mathrm{~L}_{2}{ }^{\prime}$ Twisted Trigonal Prism, J. Am. Chem. Soc., 2020, 142, 9152-9157; (l) P. Li, S. Xu, C. Yu, Z.-Y. Li, J. Xu, Z.-M. Li, L. Zou, X. Leng, S. Gao, Z. Liu, X. Liu and S. Zhang, De Novo Construction of Catenanes with Dissymmetric Cages by Space-Discriminative Post-Assembly Modification, Angew. Chem., Int. Ed., 2020, 59, 7113-7121.

6 (a) M. A. Kobaisi, S. V. Bhosale, K. Latham, A. M. Raynor and S. V. Bhosale, Functional naphthalene diimides: synthesis, properties, and applications, Chem. Rev., 2016, 116, 11685-11796; (b) S. V. Bhosale, C. H. Janiab and S. J. Langford, Chemistry of naphthalene diimides, Chem. Soc. Rev., 2008, 37, 331-342; (c) Z. Yang and X. Chen, Semiconducting perylene diimide nanostructure: multifunctional phototheranostic nanoplatform, Acc. Chem. Res., 2019, 52, 1245-1254; (d) W. Jiang, Y. Li and Z. Wang, Tailor-made rylene arrays for high performance n-channel semiconductors, Acc. Chem. Res., 2014, 47, 3135-3147; (e) J. Li, Y.-H. Hu, C.-W. Ge, H.-G. Gong and X.-K. Gao, The role of halogen bonding in improving OFET performance of a naphthalenediimide derivative, Chin. Chem. Lett., 2018, 29, 423-428; $(f)$ L. Li, J. Wang, M. Chen, Y. Chen, W. Xiao, D. Chen and M. Lin, The impact of vertical $\pi$-extension on redox mechanisms of aromatic diimide dyes, Chin. Chem. Lett., 2019, 30, 2254-2258; 
(g) S.-L. Suraru and F. Würthner, Strategies for the synthesis of functional naphthalene diimides, Angew. Chem., Int. Ed., 2014, 53, 7428-7448.

7 (a) Y. Wu, S. Schneider, C. Walter, A. H. Chowdhury, B. Bahrami, H.-C. Wu, Q. Qiao, M. F. Toney and Z. Bao, Fine-tuning semiconducting polymer self-aggregation and crystallinity enables optimal morphology and highperformance printed all-polymer solar cells, J. Am. Chem. Soc., 2020, 142, 392-406; (b) A. Sarkar, T. Behera, R. Sasmal, R. Capelli, C. Empereur-mot, J. Mahato, S. S. Agasti, G. M. Pavan, A. Chowdhury and S. J. George, Cooperative supramolecular block copolymerization for the synthesis of functional axial organic heterostructures, J. Am. Chem. Soc., 2020, 142, 11528-11539; (c) A. L. Jones, J. Jiang and K. S. Schanze, Excitation-wavelength-dependent photoinduced electron transfer in a $\pi$-conjugated diblock oligomer, J. Am. Chem. Soc., 2020, 142, 12658-12668; (d) M. Mahl, K. Shoyama, A.-M. Krause, D. Schmid and F. Würthner, Base-assisted imidization: a synthetic method for the introduction of bulky imide substituents to control packing and optical properties of naphthalene and perylene imides, Angew. Chem., Int. Ed., 2020, 59, 13401-13405; (e) A. Zhang, W. Jiang and Z. Wang, Fulvalene-embedded perylene diimide and its stable radical anion, Angew. Chem., Int. Ed., 2020, 59, 752-757; $(f)$ T. A. Barendt, L. Ferreira, I. Marques, V. Félix and P. D. Beer, Anion- and solvent-induced rotary dynamics and sensing in a perylene diimide [3]catenane, J. Am. Chem. Soc., 2017, 139, 9026-9037; (g) L. Guo, Z. Zhang and Y. Tang, Cationic conjugated polymers as signal reporter for label-free assay based on targets-mediated aggregation of perylene diimide quencher, Chin. Chem. Lett., 2018, 29, 305-308; (h) A. I. Oliva, B. Ventura, F. Würthner, A. Camara-Campos, C. A. Hunter, P. Ballester and L. Flamigni, Self-assembly of double-decker cages induced by coordination of perylene bisimide with a trimeric $\mathrm{Zn}$ porphyrin: study of the electron transfer dynamics between the two photoactive components, Dalton Trans., 2009, 4023-4037.

8 (a) A. Mizuno, Y. Shuku, R. Suizu, M. M. Matsushita, M. Tsuchiizu, D. R. Mañeru, F. Illas, V. Robert and K. Awaga, Discovery of the $\mathrm{K}_{4}$ structure formed by a triangular $\pi$ radical anion, J. Am. Chem. Soc., 2015, 137, 7612-7615; (b) L. He, L.-X. Cai, M.-H. Li, G. Zhang, L. Zhou, T. Chen, M.-J. Lin and Q.-F. Sun, Designing highly stable coordination-driven metallacycle for imaging-guided photodynamic cancer theranostics, Chem. Sci., 2020, 11, 7940-7949; (c) S. K. M. Nalluri, J. Zhou, T. Cheng, Z. Liu, M. T. Nguyen, T. Chen, H. A. Patel, M. D. Krzyaniak, W. A. Goddard III, M. R. Wasielewski and J. F. Stoddart, Discrete dimers of redox-active and fluorescent perylene diimide-based rigid isosceles triangles in the solid state, J. Am. Chem. Soc., 2019, 141, 1290-1303; (d) S. K. M. Nalluri, Z. Liu, Y. Wu, K. R. Hermann, A. Samanta, D. J. Kim, M. D. Krzyaniak, M. R. Wasielewski and J. F. Stoddart, Chiral redox-active Isosceles triangles, J. Am. Chem. Soc., 2016, 138, 5968-5977; (e) T. A. Barendt, W. K. Myers, S. P. Cornes, M. A. Lebedeva, K. Porfyrakis, I. Marques,
V. Félix and P. D. Beer, The green box: an electronically versatile perylene diimide macrocyclic host for fullerenes, J. Am. Chem. Soc., 2020, 142, 349-364; $(f)$ M. L. Ball, B. Zhang, Q. Xu, D. W. Paley, V. C. Ritter, F. Ng, M. L. Steigerwald and C. Nuckolls, Influence of molecular conformation on electron transport in giant, conjugated macrocycles, J. Am. Chem. Soc., 2018, 140, 10135-10139; (g) W. Wang, L. Wang, B. J. Palmer, G. J. Exarhos and A. D. Q. Li, Cyclization and catenation directed by molecular self-assembly, J. Am. Chem. Soc., 2006, 128, 11150-11159; (h) P. Spenst and F. Würthner, A perylene bisimide cyclophane as a "turn-on" and "turn-off" fluorescence probe, Angew. Chem., Int. Ed., 2015, 54, 10165-10168; (i) T. Türel and S. Valiyaveettil, A Naphthalene Diimide Based Macrocycle Containing Quaternary Ammonium Groups: An Electron-Deficient Host for Aromatic Carboxylate Derivatives, ChemPlusChem, 2020, 85, 1430-1437.

9 T. R. Cook and P. J. Stang, Recent developments in the preparation and chemistry of metallacycles and metallacages via coordination, Chem. Rev., 2015, 115, 7001-7045.

10 D. Zhang, T. K. Ronson and J. R. Nitschke, Functional capsules via subcomponent self-assembly, Acc. Chem. Res., 2018, 51, 2423-2436.

11 M. Paraja and S. Matile, Primary anion- $\pi$ catalysis of epoxide-opening ether cyclization into rings of different sizes: access to new reactivity, Angew. Chem., Int. Ed., 2020, 59, 6273-6277.

12 S. P. Black, A. R. Stefankiewicz, M. M. J. Smulders, D. Sattler, C. A. Schalley, J. R. Nitschke and J. K. M. Sanders, Generation of a dynamic system of three-dimensional tetrahedral polycatenanes, Angew. Chem., Int. Ed., 2013, 52, 5749-5752.

13 S. P. Black, D. M. Wood, F. B. Schwarz, T. K. Ronson, J. J. Holstein, A. R. Stefankiewicz, C. A. Schalley, J. K. M. Sanders and J. R. Nitschke, Catenation and encapsulation induce distinct reconstitutions within a dynamic library of mixed-ligand $\mathrm{Zn}_{4} \mathrm{~L}_{6}$ cages, Chem. Sci., 2016, 7, 2614-2620.

14 T. K. Ronson, D. A. Roberts, S. P. Black and J. R. Nitschke, Stacking interactions drive selective self-assembly and selfsorting of pyrene-based $\mathrm{MII}_{4} \mathrm{~L}_{6}$ architectures, J. Am. Chem. Soc., 2015, 137, 14502-14512.

15 C. M. Hong, R. G. Bergman, K. N. Raymond and F. D. Toste, Self-assembled tetrahedral hosts as supramolecular catalysts, Acc. Chem. Res., 2018, 51, 2447-2455.

16 Z. Lu, R. Lavendomme, O. Burghaus and J. R. Nitschke, A $\mathrm{Zn}_{4} \mathrm{~L}_{6}$ capsule with enhanced catalytic C-C bond formation activity upon $\mathrm{C}_{60}$ binding, Angew. Chem., Int. Ed., 2019, 58, 9073-9077.

17 Z. Lu, T. K. Ronson and J. R. Nitschke, Reversible reduction drives anion ejection and $\mathrm{C}_{60}$ binding within an $\mathrm{Fe}_{4}^{\mathrm{II}} \mathrm{L}_{6}$ cage, Chem. Sci., 2020, 11, 1097-1101.

18 S. Ganta and D. K. Chand, Multi-stimuli-responsive metallogel molded from a $\mathrm{Pd}_{2} \mathrm{~L}_{4}$-type coordination cage: selective removal of anionic dyes, Inorg. Chem., 2018, 57, 3634-3645. 
19 K. Mahata, P. D. Frischmann and F. Würthner, Giant electroactive $\mathrm{M}_{4} \mathrm{~L}_{6}$ tetrahedral host self-assembled with $\mathrm{Fe}(\mathrm{II})$ vertices and perylene bisimide dye edges, J. Am. Chem. Soc., 2013, 135, 15656-15661.

20 S. Mecozzi and J. Rebek, Jr., The 55\% solution: a formula for molecular recognition in the liquid state, Chem. - Eur. J., 1998, 4, 1016-1022.

21 A. Kaloudi-Chantzea, N. Karakostas, C. P. Raptopoulou, V. Psycharis, E. Saridakis, J. Griebel, R. Hermann and G. Pistolis, Coordination-driven self-assembly of a brilliantly fluorescent rhomboid cavitand composed of bodipy-dye subunits, J. Am. Chem. Soc., 2010, 132, 16327-16329.
22 P. D. Frischmann, V. Kunz and F. Würthner, Bright fluorescence and host-guest sensing with a nanoscale $\mathrm{M}_{4} \mathrm{~L}_{6}$ tetrahedron accessed by self-assembly of zinc-imine chelate vertices and perylene bisimide edges, Angew. Chem., Int. Ed., 2015, 54, 7285-7289.

23 P. D. Frischmann, V. Kunz, V. Stepanenko and F. Würthner, Subcomponent self-assembly of a $4 \mathrm{~nm} \mathrm{M}_{4} \mathrm{~L}_{6}$ tetrahedron with $\mathrm{Zn}^{\text {II }}$ vertices and perylene bisimide dye edges, Chem. Eur. J., 2015, 21, 2766-2769.

24 X. Feng, P. Liao, J. Jiang, J. Shi, Z. Ke and J. Zhang, Perylene diimide based imine cages for inclusion of aromatic guest molecules and visible-light photocatalysis, ChemPhotoChem, 2019, 3, 1014-1019. 